Preprints of the

Max Planck Institute for

Research on Collective Goods

Bonn 2015/15

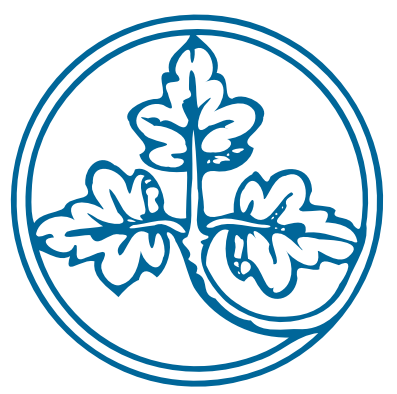

If the Worst Comes to the Worst. Dictator Giving When Recipient's Endowments are Risky

Christoph Engel Sebastian Goerg

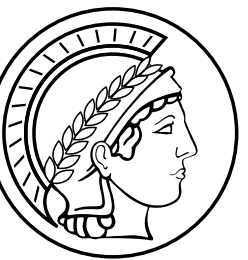




\section{If the Worst Comes to the Worst \\ Dictator Giving When Recipient's Endowments are Risky}

Christoph Engel / Sebastian Goerg

October, 2015 


\title{
If the Worst Comes to the Worst \\ Dictator Giving When Recipient's Endowments are Risky*
}

October 2015

Christoph Engel $^{* *} /$ Sebastian Goerg

\begin{abstract}
Donors may often not be sure whether a recipient really deserves their help. Does this uncertainty deter generosity? In an experiment we find that, to the contrary, under most specifications of uncertainty, dictators give more, compared with the donation the same dictator makes to a recipient they know to have the expected value of the endowment with certainty. They are particularly concerned about the possibility that a recipient leaves the lab with no payoff from the game.
\end{abstract}

JEL: C91, D03, D81

Keywords: Donation, Dictator Game, Uncertainty

Helpful comments by Anna Kochanova and Franziska Tausch on an earlier version are gratefully acknowledged.

** Corresponding author: Prof. Dr. Christoph Engel, Max Planck Institute for Research on Collective Goods, Kurt-Schumacher-Straße 10, D-53113 Bonn, Germany, phone: ++49 228 9141610, e-mail: engel@coll.mpg.de 


\section{Introduction}

People tend to be generous and consequently charities collect a substantial amount of money. Even under the controlled conditions of the lab, and with guaranteed anonymity, participants are willing to share a sizeable fraction of endowments they receive from the experimenter (Engel 2011). Yet frequently donors may not be sure that the recipient truly deserves their money. The beggar in the street may have a family that would be willing to support him. The charity may not serve the poorest of the poor, but rather those whose distress seems marketable. How do donors react to such uncertainty? Does the risk that the recipient is not really deserving help deter giving? Or do donors play it safe and keep giving to make sure that those do not suffer who really need their help? This is a question of high practical relevance. The recipient of generosity often has a hard time proving that she truly deserves help. If this certainty cannot be provided to the requisite standard, a lot of recipients might miss the help they would otherwise stand a chance to get.

In this paper, in a series of dictator games we experimentally study donations to a recipient whose deservingness is uncertain. In our baseline we provide the recipient with a fixed endowment of half the size of the dictator's endowment. We compare this baseline with situations in which the recipient's endowment is randomly drawn from distributions with different characteristics. Although we keep recipients' expected endowments fixed, dictators tend to send significantly more if recipients' endowments are risky. Comparing between differently risky endowments we find that transfers decrease in the second moment of the distribution (standard deviation - there are very wealthy and very poor recipients) and increase in the third moment (skewness - it is more likely that recipients are poor). Dictators are most generous if they know nothing about the recipient's endowment.

Our design allows us to shed additional light on these results with a series of within-subjects measures. In a separate stage, using the strategy method, we give each dictator a chance to condition transfers on the size of the recipient's endowment. For each dictator, we thus generate a complete reaction function. It turns out that only the constant of this function has explanatory power for giving if recipients' endowments are risky. How much dictators give if they know the recipient to have no endowment at all turns out to have the highest explanatory power for their choices when the recipient's endowment is uncertain. This is why we conclude that donors are most concerned about the worst of the worst for the recipient. If they cannot rule out this extreme case they become more generous. Dictators also give more if they think that other dictators give more in the same situation, suggesting that they are sensitive to what they believe to be the prevalent normative expectation.

The remainder of the paper is organized as follows: section 2 relates our paper to earlier experimental findings. Section 3 develops hypotheses. Section 4 explains the design of the experiment. Section 5 is the results section. Section 6 concludes. 


\section{Related Literature}

For our baseline, we build on a result from earlier experiments. In the standard design of the dictator game, recipients have no endowment. We know of seven studies in which recipients were given differently large endowments (Bolton and Katok 1998, Cox 2004, Eckel, Grossman et al. 2005, Bardsley 2008, Andreoni and Bernheim 2009, Carpenter, Liati et al. 2010, Korenok, Millner et al. 2012). Using a meta-study one of us has compiled, Figure 1 summarizes this evidence. The independent variable is the recipient's endowment, expressed as a fraction of the dictator's endowment. The dependent variable is the mean fraction of the own endowment the dictator gives to the recipient. The left panel is this raw data. The right panel is a bit more technical, but also more reliable. It is a graphical representation of metaregression on this data. In meta-regression, data points are weighted with the inverse of the standard error, with bubble size indicating the weight. Using this procedure one sees that the relative size of the recipient's endowment almost perfectly predicts dictator generosity (for detail see Engel 2011). ${ }^{1}$

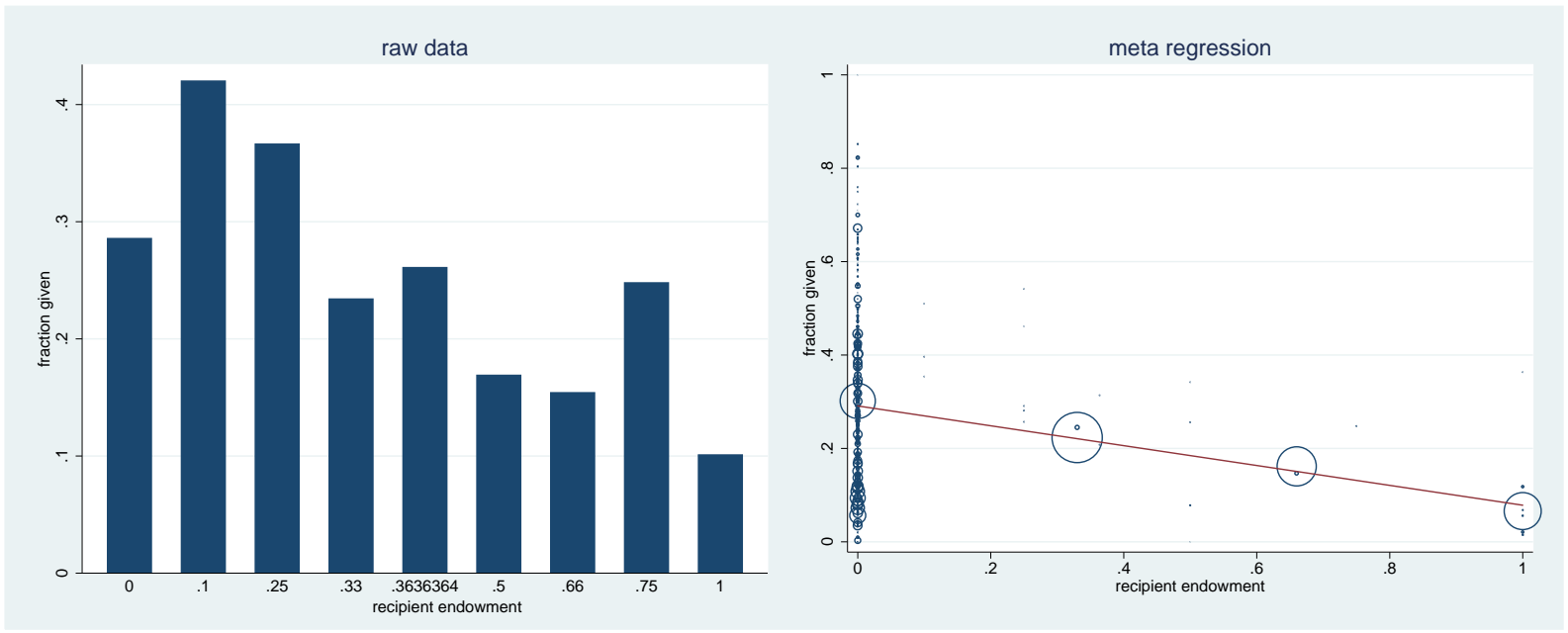

Figure 1

Dictator Generosity as a Function of Recipient Deservingness

The main contribution of our paper is a systematic investigation of the differential effect of risk about the recipient's endowment on generosity. The closest analogue is the paper by Brock, Lange et al. (2013). Similar to us they use a normal dictator game with fixed endowments as a baseline. In their treatments the dictator either has the possibility to grant the recipient a lottery with a positive expected value, or her generosity results in risky payoffs for herself. In the former case, mean generosity goes down from $21 \%$ to $15 \%$ of the dictator's endowment if the cost paid by the dictator determines the probability of the recipient getting as much as the dictator, or half as much. Generosity in the latter two cases is not distinguishable. The authors are generally interested in how social preferences extend into risky environments, but not in how risk influences the perception of recipient's deservingness. Most importantly,

1 Meta-regression over those 445 treatments for which standard errors have been reported or could be reconstructed, cons .291 ( $\mathrm{p}<.001)$, coef recipient endowment $-.213(\mathrm{p}<.001)$. 
dictators in their paper endogenously influence the risk, while we are interested in how exogenously imposed risk on recipients’ endowments influences generosity.

Similarly, Haisley and Weber (2010) have the dictator choose between a defined act of generosity and a lottery that gives the recipient nothing with probability $1 / 2$, and a small amount with the counterprobability. Alternatively the latter option is replaced by an ambiguous lottery with expected value .5. The authors find that dictators hide unfair choices behind the ambiguity. This design again differs from ours in that the risk or the ambiguity are endogenous. They are strategically chosen by the dictator to give more room for selfish behavior (cf. also Bartling, Engl et al. 2013) when they have no other possibility to avoid the opportunity or responsibility to share (Dana, Cain et al. 2006, Lazear, Malmendier et al. 2012).

The opportunity for dictators to hide behind a random process is also used by Andreoni and Bernheim (2009) who hypothesize that participants care mostly about how their actions are perceived by others, rather than being motivated by an intrinsic fairness norm. To test this hypothesis, they conduct a dictator game in which with fixed probability the dictator's choice is overridden by a move of Nature; either the recipient receives nothing, or the same amount as the dictator's endowment. Yet dictators only decide ex post, and only if they know that Nature has not intervened, allowing them to hide selfish actions behind Nature's move.

Other studies have created risk or uncertainty about the dictators' endowments. In Klempt and Pull (2009), the size of the pie to be distributed varies and either the recipient or the dictator is unaware of its actual size. Frignani and Ponti (2012) create uncertainty about which of two players has the higher endowment, and give one of them a chance to choose between two allocations. They compare these choices with a setting where there is only the distributional problem, but no uncertainty, and another setting where there is only the uncertainty, but no distributional problem. Through the veil of ignorance manipulation, one learns how strongly distributional choice suffers from self-serving bias.

Fong (2007) presents evidence from a field experiment that generosity depends on the way neediness is presented. Student donors are asked whether they want to give some of their endowment to one of three women on welfare. Potential recipients had filled out a questionnaire about their background and their attempts to lead an autonomous life. One of the three women had provided little information, creating uncertainty about how deserving she actually was. The second woman's questionnaire conveyed the impression of her being rather lazy, while the third woman's questionnaire made it clear that she had done whatever she could to earn her living herself. The recipient who had given little information received the highest donations.

Further papers, manipulating the presentation or availability of information in dictator games, are rather remote. In Koch and Normann (2008), recipients do not know how the money has been generated. In Cappelen, Konow et al. (2013), the decision to accept a lottery creates the inequality that may be changed by a dictator. In Iriberri and Rey-Biel (2011) players either 
know or do not know when choosing an allocation whether they will have the active or the passive role. In Van Koten, Ortmann et al. (2013), the size of the pie to be distributed is not fully known. In Heinrich and Weimann (2013), one of multiple allocation tasks is either chosen by one of the two parties or at random. In Yamagishi and Mifune (2008) dictators know the social background of recipients, but not vice versa. In Norton, Lamberton et al. (2013), the social background of the recipient is or is not ambiguous. In Branas-Garza, Durán et al. (2009), dictators can delegate decisions to a randomization device. In Fong and OberholzerGee (2011), dictators can buy a costly signal to learn how deserving a real world recipient actually is. Brennan, González et al. (2008) do not find a correlation between preferences regarding risk for one's own payoff, and for the payoff of others. In the dictator games of Caballero (2014) an effort stage determines the endowments and dictators receive information on receivers' opportunities and effort. Winschel and Zahn (2014) introduce information asymmetries on the benefits of dictators' actions. Uninformed dictators who do not know exactly how the recipient benefits from her actions behave more pro-socially than informed dictators who know the benefit with certainty.

\section{Hypotheses}

In our experiment we compare the generosity towards recipients with fixed and randomly determined endowments. If dictators hold standard preferences, they will give nothing to the recipient, irrespective of the recipient's endowment and, consequently, irrespective of it being fixed or randomly determined. Given previously discussed findings on the dictator game and the literature on social preferences in general, we expect positive transfers by some subjects. For example, based on the linear model by Fehr and Schmidt (1999) a dictator in the classical dictator game gives an amount that equalizes earnings provided she is sufficiently averse against advantageous inequity, i.e. provided $\beta>\frac{1}{2}$, as specified in (1)

$$
u_{d}=e_{d}-x-\beta\left(e_{d}-x-e_{r}-x\right)
$$

, where $u$ is utility, $d$ is the dictator, $r$ is the recipient, $e$ is the endowment, $x$ is the amount transferred from the dictator to the recipient, and $\beta$ measures the degree of aversion against advantageous inequity.

Originally, inequity aversion has been specified for outcomes that are free from risk. However, there are two obvious ways to extend it to situations involving risk: randomly determined endowments could either affect the assessment of fairness ex-ante or ex-post. ${ }^{2}$

2 It is worth noting that the approach based on ex ante fairness is inconsistent with utilitarianism since it violates the independence axiom (Fudenberg and Levine 2012, Sandroni, Ludwig et al. 2013). Using expected utility theory would violate ex-ante fairness, while ex-ante fairness is not compatible with ex-post fairness. Fudenberg and Levine (2012) demonstrate that this holds not only for the model by Fehr and Schmidt (1999), but also for the social preference models by Bolton and Ockenfels (2000), Charness and Rabin (2002), and Andreoni and Miller (2002). 
If dictators care about fairness ex-ante, i.e., fairness before the realization of the endowment is known, they would base their decision on the expected value of the endowment and maximize their utility defined by $u_{d}\left(e_{d}, E\left(e_{r}\right), x\right)$; this is the assumption made in the adaptation of the model by Trautmann (2009). An ex-ante inequity averse dictator would transfer the same amount to a recipient with a fixed endowment as she transfers to a recipient with the same expected endowment. Therefore, our nul hypothesis postulates no treatment differences, regardless whether subjects are self-centered money maximizers or ex-ante inequity averse.

$\mathbf{H}_{\mathbf{0}}$ : $\quad$ Dictators will always transfer the same amount as long as recipients' endowments are constant in expectation.

However, if dictators care about fairness ex-post, all possible realizations of inequities would be taken into account and weighted with the corresponding probabilities. Thus, a dictator with ex-post fairness concerns maximizes the expected utility $E\left(u_{d}\left(e_{d}, \widetilde{e_{r}}, x\right)\right)$, where $\widetilde{e_{r}}$ is any realization of the recipient's endowment made possible by the situation (or the design of the experiment, for that matter). In addition to the situations with advantageous inequity this would now include situations where the payoff balance is to the dictator's disadvantage. Disadvantageous inequity could either result from a larger initial endowment for the recipient or be generated by the dictator herself giving too much, given the actual endowment of the recipient. In the model by Fehr and Schmidt (1999), this would involve an additional $\alpha$-term capturing the aversion against disadvantageous inequity. This would imply:

$\mathbf{H}_{1}$ : $\quad$ Dictators will transfer different amounts when recipients' endowments are fixed or randomly taken from distributions, even if recipients' endowments are equal in expectations

Obviously the predicted differences between the treatments depend on the exact distribution of parameters as they translate into advantageous and disadvantageous inequity. ${ }^{3}$ However, keeping the expected value constant we can identify two opposing effects, which can be linked to the second and third moments of the distributions of the recipients' endowments. ${ }^{4}$

First, increasing the standard deviation (second moment) of the distribution increases the differences between the potentially resulting initial endowments and the corresponding expected endowments. Given that on average the aversion against disadvantageous inequity is stronger than the one against advantageous inequity, a higher weight should be on the cases with disadvantageous inequity. Therefore, keeping the expected endowment of a recipient fixed, a dictator would be less generous if the endowment is drawn from a distribution with a larger standard deviation, compared with a distribution with a smaller standard deviation. Second,

3 Table A1 in the appendix gives the conditions for the $\beta$ parameter that need to be fulfilled for a positive transfer, separately for each treatment; of course no such condition can be calculated if the distribution is not revealed to participants.

4 In principle, one could of course also consider yet higher moments of the distribution. We refrain from offering hypotheses since we do not manipulate kurtosis and further moments of the distribution in our experiment. 
increasing the skewness (third moment) of the distribution shifts the mass of possible recipient endowments closer to zero, thereby increasing the incidences of advantageous inequity. Thus, a dictator who is sufficiently averse to advantageous inequity should increase her generosity to prevent the recipient from earning nothing or very little. These considerations yield two directional hypotheses:

$\mathbf{H}_{2}$ : $\quad$ Keeping the expectation constant,

a.) a larger standard deviation of recipients' endowments reduces generosity

b.) a larger skewness of recipients’ endowments increases generosity.

The previously discussed hypotheses are for situations in which dictators know the recipients' exact endowment, or at least the expected value and the distribution from which the endowment is drawn. Technically, this condition is still fulfilled if the recipient's endowment is taken from a compound lottery. But experimental participants are likely to perceive a compound lottery as an object that is (too) difficult to understand, which makes this a borderline case to an ambiguous situation. The situation is even technically ambiguous if participants are only told the expected value, but have no further information on the distribution from which the recipient's endowment is taken. Uncertainty in the technical sense exists if participants are not given any information about the recipient's endowment. In this situation participants must replace objective with subjective values (Savage 1954). While, we have no theoretical reason to predict the direction of the effect it is reasonable to assume that subjective values differ, which should result in more heterogeneous transfers. This leads to

$\mathbf{H}_{3}$ : The distribution of dictators' choices differs if they have no information on the recipient's endowment, compared with dictators who receive objective information about this distribution.

\section{Design and Procedures}

Our experiment consists of several stages and the treatments are implemented in the second stage. The first stage, as well as the stages following the treatments, provide a series of additional within-subjects controls that inform us about the potential forces driving dictator choices. They are the same for all participants. Participants are assigned either to the role of the dictator or a passive recipient. The assigned role is fixed for the duration of the experiment. After the first stage dictators and receivers are randomly re-matched. To preserve independence, feedback on earlier parts of the experiment is withheld until the very end of the entire experiment.

In the first stage we measure each dictators' conditional generosity given varying initial endowments of the recipient. Using the strategy method (Selten 1967), we elicit a complete reaction function, asking participants to tell us how much they would give to the recipient provided the recipient has an endowment of $0 €$ to $10 €$, in equal steps of $1 €$, and her own en- 
dowment being fixed at $10 €$. After dictators have made all choices, the computer randomly determines the recipient's endowment, and executes the choice the dictator has made for this case. Feedback from this part of the experiment is withheld until the very end of the experiment.

In the second stage, we implement the treatments and every dictator decides on one transfer for a given distribution from which recipients' endowments are determined. In fixed, our baseline treatment, we conduct a standard dictator game with the only feature that the potential recipient also has an endowment. While the dictator is endowed with $10 €$, the potential recipient is endowed with $5 €$. The remaining nine treatments differ from fixed by the fact that the dictator is at best incompletely informed about the recipient's endowment. In the symmetry treatment, with 50\% probability the recipient has no endowment. With the counter probability of also $50 \%$, her endowment is the same as the dictator's endowment, i.e. $10 €$. In the right asymmetry treatment, the recipient's endowment is $0 €$ with $90 \%$ probability, and $50 €$ with $10 \%$ probability. In the left asymmetry treatment, the recipient's endowment is $0 €$ with $10 \%$ probability, and $5.5 €$ with $90 \%$ probability. In the uniform treatment, with $9.09 \%$ probability the recipient's endowment may assume any integer value between $0 €$ and $10 €$. In the right skewed and left skewed treatments, the recipient's endowment may also assume 11 different realizations, but the distribution is convex (right skewed) or concave (left skewed). For the exact shape of the distributions, please see the instructions in the appendix. In the state space treatment, with equal probability of one third, the realization of the recipient's endowment is taken from the uniform, right skewed or left skewed distribution. In the expected value treatment, the only information the dictator receives about the recipient's endowment is the expected value of $5 €$. Finally, in the ignorance treatment the dictator is told that she will not be informed about the recipient's endowment.

In all but the ignorance treatment, the dictator knows that in expectation the recipient's endowment is $5 €$. We have three treatments with a binary state space. In four treatments, the recipient's endowment may assume 11 different realizations. In the State Space treatment, 33 realizations are possible. In the final two treatments, the dictator is not informed about the possible number of realizations. Standard deviations run from 1.65 (left asymmetry) to 15.00 (right asymmetry). Skewness runs from -2.67 (left asymmetry) to 2.67 (right asymmetry). Table 1 summarizes the treatment variation. 


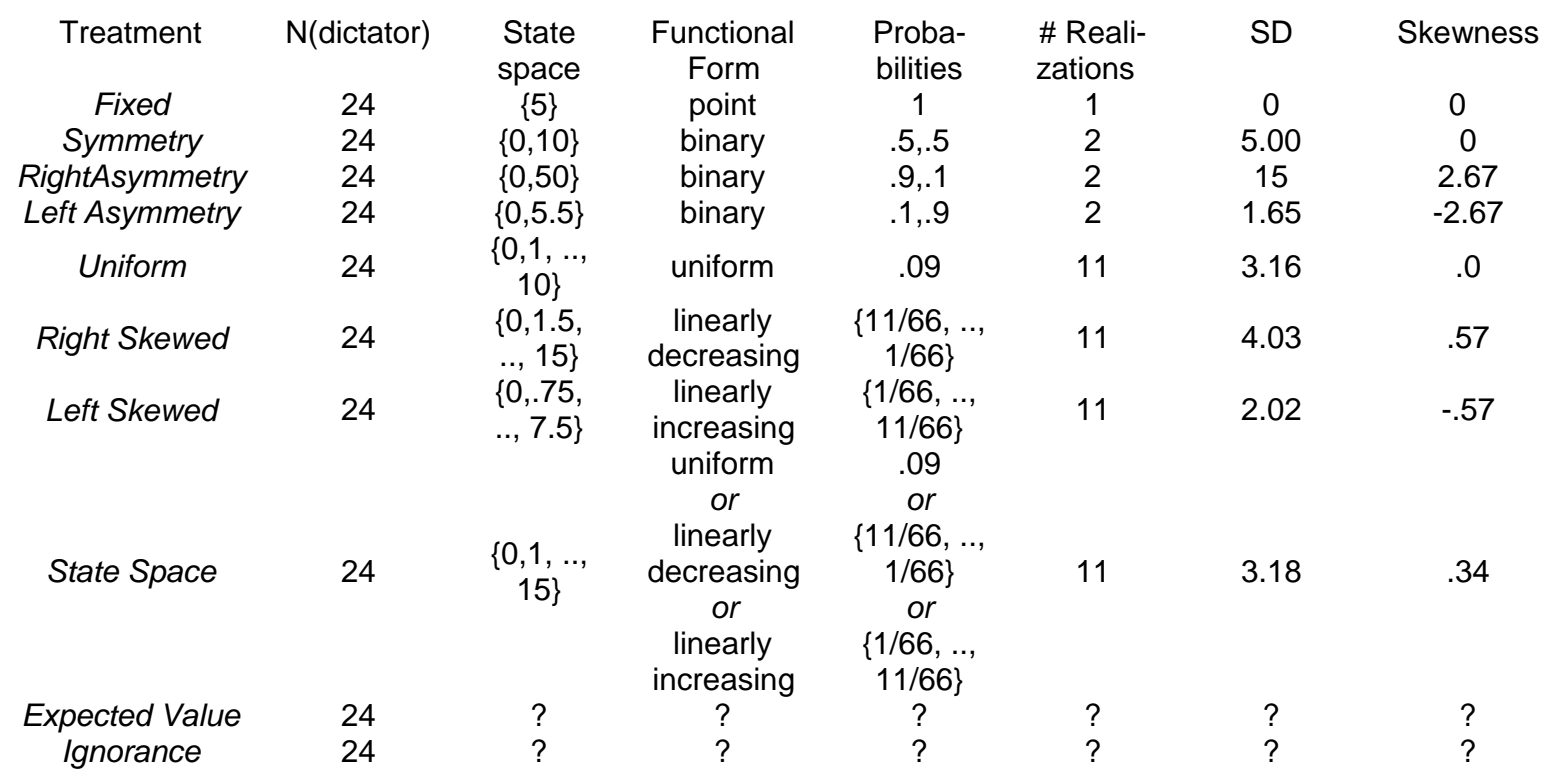

Table 1

Treatments - Distributions the Recipients' Endowments are Taken From

In all treatments except in ignorance,

participants know the expected value of the recipient's endowment to be $5 €$

Since it is known that untrained individuals have problems processing probability information, we represent all probabilities by natural frequencies, taken from 10,000 possible situations; this format has been documented to substantially reduce cognitive errors (Gigerenzer and Hoffrage 1995). All probabilities and payoffs are not only represented numerically, but also graphically. Please see instructions for detail.

After the second stage we run a series of additional tests and questionnaires. We first elicit two beliefs. We ask all participants how much they believe dictators have on average given if they knew as much about the recipient's endowment as in the main experiment. We also ask how much participants believe dictators have on average given in the one case of the within subjects tests where they know recipients to receive $5 €$. Participants earn $1 €$ if either estimate is no more than 1 unit away from the actual number. In all treatments, dictators do not know the recipient's endowment for sure. To check whether they evaluate this situation with their personal risk preference, we measure risk attitudes, using the standard test by Holt and Laury (2002). ${ }^{5}$ In the ignorance and in the expected value treatments, dictators face ambiguity. In the state space treatment participants might construct the lottery as well as ambiguous. This is why we also measure dictators' ambiguity aversion, using the test proposed by Shupp, Sheremeta et al. (2013). Dictator reactions to recipient's endowment that are risky might be conditional on their individual degree of generosity. We gain this control variable from the ring measure of social value orientation (Liebrand and McClintock 1988). ${ }^{6}$ Finally, using the

5 We also administer the alternative test proposed by Eckel and Grossman (2008). Since results look very similar, we do not report them.

6 In the questionnaire, we also administer the 10 item version of the Big 5 inventory (Rammstedt and John 2007), ask risk and trust questions from the German socio-economic panel, and collect demographic in- 
mechanism introduced by Becker, DeGroot et al. (1964), from each participant we elicit the willingness to accept for selling a lottery with the same characteristics as the lottery that determines the recipient's endowment.

The experiment was run in 2013 and 2014 in the Bonn EconLab. 478 participants randomly drawn from a pool of approximately 6000 participated in the experiment. Each participant only played a single treatment, and had no information about the remaining treatments. 239 participants had the active, and 239 had the passive role. ${ }^{7}$ Roles were randomly assigned at the beginning of the experiment, and held constant throughout the experiment. 272 (56.9\%) were female. Mean age was 23.28 years. 456 (95.4\%) were students of various majors. The experiment was programmed in zTree (Fischbacher 2007). Participants were invited using the software ORSEE (Greiner 2004). Participants had to answer control questions for the dictator game using the strategy method, and for the main experiment. Feedback from all parts of the experiment was withheld until the very end of the experiment. The experiment approximately lasted two hours. Participants on average earned $29.24 €$ (39.30 \$), $31.85 €$ for dictators, and $26.58 €$ for recipients.

\section{Results}

As a first step of our analysis we investigate within-subject differences between first and second stage choices. Thereafter, we turn to comparisons across treatments and analyze the driving forces behind the observed behavior.

\section{a) Within subject differences if recipients' endowments are fixed or risky}

In the first stage, dictators chose their contributions conditional on the recipient's endowment, while in the second stage they decided on transfers given different distributions from which the recipient's endowments are taken. In the first stage we asked dictators how much of $10 €$ they are willing to give to a passive recipient who has an endowment between 0 and $10 €$, in equal steps of $1 €$. In all but the ignorance treatment second stage, dictators know recipient endowments in expectation to be equal to $5 €$.

Overall, first stage transfers (if the endowment is $5 €$, i.e. the expected value in the second stage) are highly and significantly correlated with second stage transfers ( $\rho=0.5695, \mathrm{p}<$ 0.001 , Spearman rank correlation). However, depending on treatment, there exist significant differences between transfers with a fixed and a randomly determined endowment. Figure 2 reports mean differences between second and first stage transfers.

formation. We also ask recipients about their expectations regarding dictators' choices. Since we can make all points with incentivized tests, we do not use this information for the present paper.

7 In the ignorance treatment, we could not fill one group of 2 since invited participants did not show up. 
Not surprisingly, we observe no significant difference between first and second stage transfers in our baseline treatment fixed, where recipients' second stage endowment was fixed to 5 (diff $=.125$, two-sided signrank test of diff $=0, \mathrm{~N}=24, \mathrm{p}=.7605)$. In treatment expected value first and second stage choices are also very similar (diff $=.042, \mathrm{p}=.7605)$. This suggests that subjects (mis)interpret the expected value as if they knew the realization of the recipient's endowment with certainty. In all other treatments, dictators transfer higher amounts when the recipients' endowments is risky. In left asymmetry (diff $=.208, \mathrm{p}=.2609$ ) this difference is not significant. It is weakly significant in treatments right asymmetry (diff $=.375, \mathrm{p}=.0528)$, right skew (diff $=.375, \mathrm{p}=.0919)$, uniform (diff $=.500, \mathrm{p}=.0997)$, left skew (diff $=.542, \mathrm{p}=$ .0722 ), and state space (diff $=.583, \mathrm{p}=.0625$ ), in symmetry it is significant at conventional levels (diff $=.667, \mathrm{p}<0.0187$ ) and in ignorance it is highly significant (diff $=1.087, \mathrm{p}=$ $.0004)$.

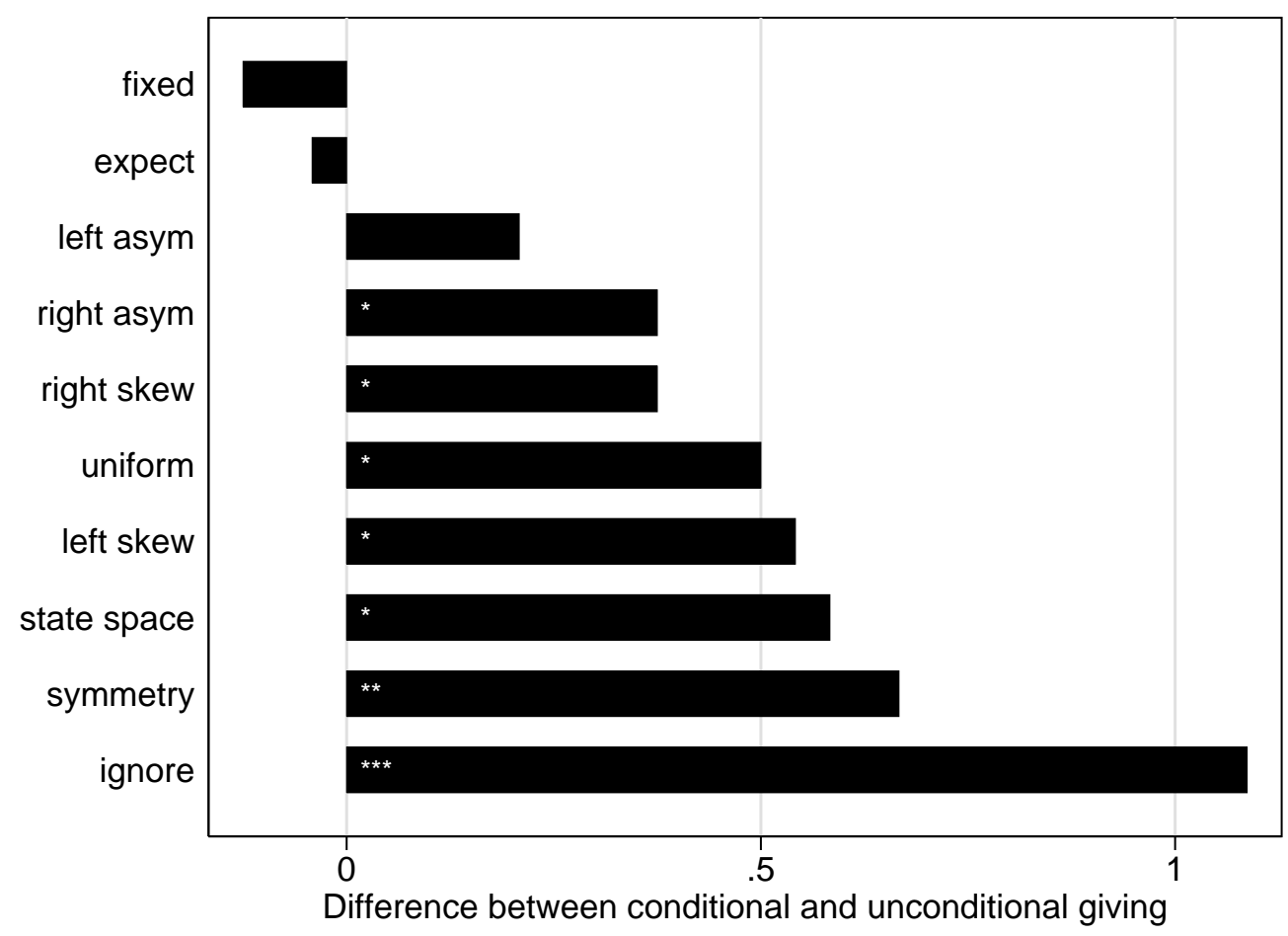

Figure 2

\footnotetext{
Mean Difference Between Unconditional (stage 2) and Conditional (stage 2) Giving

stage 1 giving is for recipient having an endowment of $5 €$

stars denote the significance levels of two-sided one-sample signrank test, ${ }^{\star} p<0.1 ;{ }^{* *} p<0.05 ;{ }^{\star \star *} p<0.01$
}

In the previous analysis we only used a single conditional choice. We compared the unconditional transfer with the conditional transfer when the recipients' endowment equaled the expected value of the unconditional choice, i.e. when the recipient was endowed with $5 €$. We now alternatively use all 11 conditional transfers. We predict which unconditional choices participants would have made had they precisely matched their conditional transfers. We thus map conditional choices on each possible realization of the lottery, and weigh it with the fre- 
quency that this realization obtains in expectation. ${ }^{8}$ Of course we can only use this procedure for treatments symmetry, right asymmetry, left asymmetry, uniform, right skewed, left skewed and state space. Figure 3 shows the resulting mapping of predicted and observed transfers; dots represent unconditional (stage 2) transfers of dictators who have made at least one positive transfer in stage 1 and squares represent unconditional transfers of dictators who never transferred a positive amount in stage 1 . The closer dots and squares are to the line, the closer the predicted behavior is to the observed behavior. In general, observations are roughly in line with predictions. However in most treatments dictators are more generous when the recipients' endowment is risky (there are more dots and squares above than below the line). We thus have further support for the finding that participants are more generous if the recipient's endowment is risky.

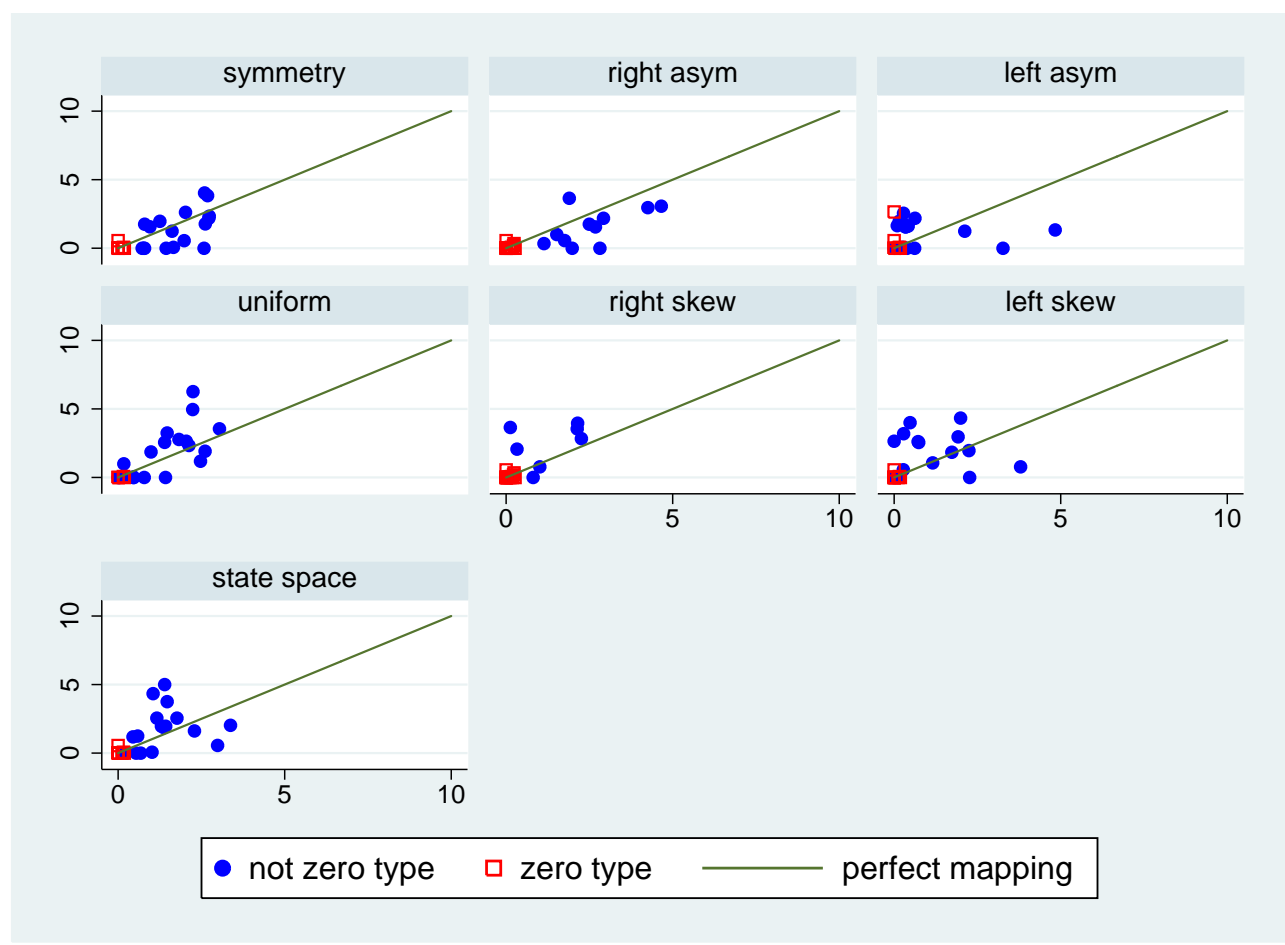

Figure 3

Mapping of Choices from Certain to Risky Recipients' Endowments

x-axis: predicted amount, y-axis: actual amount

This visual impression is supported by the regressions in Table $2 .{ }^{9}$ First stage behavior is a highly significant predictor of second stage transfers. The positive coefficient indicates that

8 To illustrate the approach take the symmetry treatment. In this treatment, with $50 \%$ probability the recipient's endowment is 0 , while it is 10 with the counterprobability of also $50 \%$. If unaffected by risk the participant would make an intermediate choice, given by $.5^{*}$ her choice if she knows for sure that the recipient has no endowment, and $.5^{*}$ her choice if she knows that the recipient has the same endowment as herself, i.e. 10. If the recipient may have an endowment $>10$, we map it onto her certain choice if the recipient's endowment is 10 . If treatments allow for non-integer recipient endowment, for mapping we round up to the next integer. This mapping is not feasible for the expected value and ignorance treatments.

9 We estimate a Tobit model, rather than a double hurdle model, since in this regression the explanatory variable already captures zero types (by the prediction that they will give nothing); see below b) for further discussion. 
predictions and choices are positively correlated (model 1). If we control for the square of the prediction, the coefficient of the prediction is substantially larger than the constant (model 2). This implies that dictators give even more in the second stage, the more so the less they are generous if they know the recipient's endowment with certainty. This effect only disappears if the participant is predicted to give more than half her endowment (which is very rare, given the strong effect of aversion against disadvantageous inequity aversion). ${ }^{10}$

\begin{tabular}{|l|l|l|}
\hline & model 1 & model 2 \\
\hline prediction & $\begin{array}{l}1.507^{\star \star \star} \\
(.193)\end{array}$ & $\begin{array}{l}3.425^{\star \star \star} \\
(.469)\end{array}$ \\
\hline \multirow{2}{*}{ prediction $^{2}$} & & $\begin{array}{l}-.614^{\star \star \star} \\
(.126)\end{array}$ \\
\hline \multirow{2}{*}{ cons } & $\begin{array}{l}-1.626^{\star \star \star} \\
(.356)\end{array}$ & $\begin{array}{l}-2.155^{\star \star \star} \\
(.395)\end{array}$ \\
\hline p model & $<.001$ & $<.001$ \\
\hline $\mathrm{N}$ & 180 & 180 \\
\hline
\end{tabular}

Table 2

Mapping of Choices from Certain to Risky Recipients' Endowments

Tobit, lower limit 0

data from the symmetry,right asymmetry, left asymmetry, uniform, right skewed, left skewed, state space treatments standard errors in parenthesis

$\star \star \star ~ p<.001$

Based on these within-subject results, we can already reject our nul hypothesis. In line with hypothesis $\mathbf{H}_{\mathbf{1}}$ dictators send different amounts if recipients' endowments are no longer fixed but randomly determined. In most of the treatments this leads to significantly higher transfers to the recipient. We thus have our first result:

Result 1: If dictators only know the expected value of the recipients' endowment, they tend to send the same amount as if the recipient had this endowment for sure. However, they tend to send significantly more if recipients' endowments are randomly taken from a known distribution.

\section{b) Dictator reactions to recipients' endowment with different specifications of risk}

We now turn to the second stage behavior of subjects and compare it across treatments. Testing the second stage transfers reveals at a first glance no significant differences $(p=0.1547$, Kruskal-Wallis test). However, it is well known that social preferences are heterogeneous and that a substantial fraction of the experimental population behaves selfishly in dictator games (Engel 2011:Fig.2), making it hard to observe treatment differences. However, it is plausible that a substantial fraction of dictators who give nothing when recipients' endowments are randomly determined don't do so because they are selfish, but because they doubt that the recipi- 
ent really needs help. In principle this creates an econometric challenge. One must find a way of telling apart zero giving as a result of personality ("zero type”) and of situation (participants would in principle be willing to give a positive amount to a truly deserving recipient, but doubt deservingness in the case at hand). The strength of our design is that we are not forced to infer selfish types from the ultimate dictator choices, but rather can use the conditional dictator choices from the first stage to identify these types. Specifically we observe if the dictator never gives a positive amount for fixed endowments and, thus, is fully selfish. 81 dictators are selfish according to this criterion. By contrast 158 dictators have at least one positive transfer in the first stage, and are therefore not classified as selfish types for fixed endowments. Reinvestigating the transfers between treatments for the subsample of dictators who are not selfish as a matter of principle reveals indeed signs that transfers differ significantly between treatments ( $\mathrm{p}=0.0725$, Kruskal-Wallis test).

With parametric estimation we can analyze treatment effects more precisely. The most appropriate approach for our data-generating process is a double hurdle model (Cragg 1971). It not only allows for heterogeneous types, but assumes two independent reasons why a dictator might give nothing to a recipient. ${ }^{11}$ She may be selfish, or she may deem the recipient not deserving in this particular situation. ${ }^{12}$ Hence the statistical model is given by

$$
\begin{aligned}
& d_{u}^{*}=\gamma_{0}+\gamma_{1} d_{c}+\varepsilon_{d} \\
& g_{u}^{* *}=\beta_{0}+\beta_{1} t+\varepsilon_{g} \\
& g_{u}=\mathbf{1}\left(d_{u}^{*}=1\right) \mathbf{1}\left(g_{u}^{* *}>0\right) g_{u}^{* *}
\end{aligned}
$$

where $d_{u}$ is a latent dummy variable that is 1 if the participant is not a selfish type. $g_{u}^{* *}$ is a second latent variable, which we explain by treatment $t$. This latent variable translates into giving nothing (not passing the second hurdle) provided the latent variable is negative or zero. If (1) the first hurdle is passed (the participant is not a selfish type, $d_{u}{ }^{*}>0$ ) and (2) the second hurdle is passed (the participant does not react to the specification of risk induced by the treatment by giving nothing), the individual gives fraction $g_{u}$ of her endowment. We estimate whether a participant is a selfish type with a dummy variable that is 1 if the dictator gives a positive amount for at least one level of recipient endowment in the first stage (variable $d_{c}$ ).

If we use this procedure to filter out selfish types, we observe similar results as with our within-subject analyses. No significant treatment difference compared with the baseline fixed, for the right asymmetry, left asymmetry and the expected value treatments. But we do find significant treatment effects for all other treatments, i.e. the symmetry, ${ }^{13}$ the uniform, the right skewed, the left skewed, and the state space treatment (Table 3 Model 1). In Model 2 we direct-

11 Often Tobit models that allow for lower censoring are applied to dictator games. However, a Tobit model makes the problematic assumption that participants who have given nothing might as well also have taken money. More importantly even, Tobit maintains the assumption that dictators are taken from a homogenous population.

12 For background and software implementation see Engel and Moffatt (2014).

$13 \mathrm{p}=.065$. 
ly test hypotheses $\mathbf{H}_{\mathbf{2 a}}$ and $\mathbf{H}_{\mathbf{2 b}}$. If recipients' endowments are randomly taken from a distribution (i.e. if the data are not from the fixed baseline), dictators tend to transfer significantly more. However the skewness and the standard deviation of the underlying distribution influence the actual size of the transfer. The effect of the standard deviation is at first only weakly significant, but turns significant at conventional levels if we control for the number of possible realizations that the recipient's endowment may take (model 3, see Table 1 for detail). ${ }^{14}$ In line with our predictions we find a negative effect of the standard deviation, and a positive effect of skewness. The more the possible realizations of the recipient's endowment are spread out, the less even those dictators are willing to give that are not selfish in the first place. Skewness has a positive value if it is quite likely that the recipient has nothing or little (cf. Table 1).

While we had directed hypotheses for the effects of the standard deviation and skewness we did not expect transfers to be higher in all treatments compared to the baseline with fixed endowment of $5 €$. In treatments right asymmetry and right skewed the dictator can end up with a lower profit than the recipient, even if the dictator gives nothing (Table 1). And still, we observe a significantly positive effect if we compare these two treatments with the baseline (double hurdle model, coef 1.032, se .487, p .034). The effect becomes even stronger if we compare the fixed treatment with all treatments where the recipient may have a higher or the same endowment as the dictator. This is additionally possible in the treatments symmetry, uniform, and state space (double hurdle model, coef 1.259, se .480, p .009). We thus conclude,

Result 2: Dictators who are at all willing to donate give more if the recipient's endowment is not fixed but randomly determined. Transfers decrease with increased standard deviation and increase with increased skewness.

14 Standard deviation $(\mathrm{p}=.063)$, skewness $(\mathrm{p}=.049)$. 


\begin{tabular}{|c|c|c|c|}
\hline & model 1 & model 2 & model 3 \\
\hline \multicolumn{4}{|l|}{ if hurdle passed } \\
\hline symmetry & $\begin{array}{l}1.169^{+} \\
(.635)\end{array}$ & & \\
\hline right asymmetry & $\begin{array}{l}.951 \\
(.658) \\
\end{array}$ & & \\
\hline left asymmetry & $\begin{array}{l}.564 \\
(.616) \\
\end{array}$ & & \\
\hline uniform & $\begin{array}{l}1.706^{\star \star} \\
(.596)\end{array}$ & & \\
\hline right skewed & $\begin{array}{l}1.727^{*} \\
(.710) \\
\end{array}$ & & \\
\hline left skewed & $\begin{array}{l}1.317^{*} \\
(.592)\end{array}$ & & \\
\hline state space & $\begin{array}{l}1.268^{*} \\
(.583)\end{array}$ & & \\
\hline expected value & $\begin{array}{l}.573 \\
(.629)\end{array}$ & & \\
\hline ignorance & $\begin{array}{l}2.013^{\star \star \star} \\
(.565) \\
\end{array}$ & & \\
\hline recipient's endowment risky & & $\begin{array}{l}1.624^{\star \star} \\
(.521)\end{array}$ & $\begin{array}{l}2.094^{\star \star} \\
(.690)\end{array}$ \\
\hline standard deviation & & $\begin{array}{l}-.112+ \\
(.060) \\
\end{array}$ & $\begin{array}{l}-.174^{\star} \\
(.084) \\
\end{array}$ \\
\hline skewness & & $\begin{array}{l}.339^{*} \\
(.172)\end{array}$ & $\begin{array}{l}.500^{\star} \\
(.231)\end{array}$ \\
\hline number of possible realizations of recipient's endowment & & & $\begin{array}{l}-.018 \\
(.018) \\
\end{array}$ \\
\hline cons & $\begin{array}{l}1.044^{*} \\
(.459)\end{array}$ & $\begin{array}{l}1.247^{\star \star} \\
(.425) \\
\end{array}$ & $\begin{array}{l}1.277^{\star \star} \\
(.421) \\
\end{array}$ \\
\hline \multicolumn{4}{|l|}{ hurdle } \\
\hline does not always give nothing if recipient endowment is certain & $\begin{array}{l}2.811^{\star \star \star} \\
(.407)\end{array}$ & $\begin{array}{l}2.552^{\star \star \star} \\
(.409)\end{array}$ & $\begin{array}{l}2.552^{\star \star \star} \\
(.420)\end{array}$ \\
\hline cons & $\begin{array}{l}-2.224^{\star \star \star} \\
(.386)\end{array}$ & $\begin{array}{l}-2.172^{\star \star \star} \\
(.393)\end{array}$ & $\begin{array}{l}-2.172^{\star * \star} \\
(.393) \\
\end{array}$ \\
\hline \multicolumn{4}{|l|}{ model characteristics } \\
\hline p model & $<.0001$ & $<.0001$ & $<.0001$ \\
\hline N & 239 & 192 & 192 \\
\hline
\end{tabular}

Table 3: Treatment Effects

double hurdle models

model 1: all data; model 2 and 3: all data except treatments ignorance and expected value

standard errors in parenthesis

${ }^{\star * *} p<.001,{ }^{* *} p<.01,{ }^{*} p<.05,{ }^{+} p<.1$

The one treatment that clearly stands out is ignorance. Already Figure 2 reveals that the largest effect is observed in the situation in which dictators have no information on the recipients' endowment whatsoever. In line with this the coefficient of this treatment in Model 1 of Table 3 has the highest positive value. Our previous within-subject analysis confirmed that subjects were willing to transfer significantly more if they had no information on recipients' endowment, compared to recipients with a fixed endowment of $5 €(\mathrm{p}<0.001$, two-sided signrank test). We further highlight this point by comparing the second stage behavior between treatments fixed and ignorance. In our baseline treatment fixed, i.e. when dictators knew that the recipient had half their own endowment, $58 \%$ of them kept the entire endowment for themselves. At most they gave 2 of $10 €$, which leads to slightly less than an equal split of earn- 
ings. By contrast if dictators had no clue about the recipient's endowment, they on average gave $2 €$. The maximum was $8 €$. Only 35\% of all dictators kept the entire endowment. The between subjects difference in giving is significant for the comparison between ignorance and fixed ( $\mathrm{p}=.0212$, two-sided Mann-Whitney test) and for the comparison between ignorance and all other treatments pooled ( $\mathrm{p}=.0104)$. We thus fully support $\mathbf{H}_{3}$ and identified the direction of the effect:

Result 3: Dictators give the most if they do not know anything about the recipient's endowment.

\section{c) Explanations}

Can we explain that dictators become more generous if recipients' endowments are no longer fixed? In Table 4, we try to identify some of the underlying factors, using the data from the within subjects tests.

We already mentioned that the conditional transfers from the first stage give us a complete reaction function. To characterize this function, separately for each dictator, we run a local linear regression that explains choices with each of these 11 recipients' endowments and their square (to capture non-linearities). Separately for each participant, we thus regress $g_{c r}=$ $\gamma_{0}+\gamma_{1} e_{r}+\gamma_{2} e_{r}^{2}+\varepsilon_{r}$, where $g$ is the amount given conditional (c) on the recipients endowment being $r$. $e$ is the respective certain endowment of the recipient, and $e^{2}$ is its square. From each dictator we thus have three coefficients: the constant $\gamma_{0}$, the slope $\gamma_{1}$, and the square term $\gamma_{2}$. As model 1 of Table 4 demonstrates, only the constant has explanatory power. This intercept is a linear approximation of the respective dictator's willingness to donate if the recipient's endowment is 0 . This interpretation receives additional support from model 2. In this regression, we explain dictators' second stage choices with two of their choices under certainty: if the recipient has no endowment, and if the recipient receives the expected value of the lottery from the main experiment. Both choices under certainty have a positive effect on choices with risky endowments. But the effect of the dictator's choice when she knows that the recipient has no endowment is much bigger and significant at the $1 \%$ level. By contrast, the effect of the dictator's choice when she knows that the recipient receives $5 €$ is less than half that strong and only weakly significant $(\mathrm{p}=.055)$. This suggests that dictators are particularly concerned about the risk that recipients might not gain anything from the game.

Model 3 provides additional support for this interpretation. If we control for the expectations of dictators about the average choice of dictators in the main experiment and when they know the recipient to have a certain endowment of $5 €$, the effect of the dictator's choice when she knows that the recipient is endowed with $5 €$ becomes insignificant, as does the corresponding belief about the choices of all dictators. By contrast, the effect of the dictator's own decision when she knows the recipient to be poor remains highly significant and almost as strong as before. Additionally there is an even stronger, and also highly significant, effect of the dictator's expectation about the choices of all dictators in the main experiment. This suggests that 
dictators consider leaving recipients with nothing as normatively problematic, and that they give the more the more demanding their belief about this norm.

If we further control for the dictator's generosity, as expressed in her social value orientation, we find the expected positive correlation (model 4). The more pro-social the dictator (according to her social value orientation), the higher the transfers in the risky dictator game. Interestingly, the coefficient of dictators' expectations about the choices of all dictators in the main experiment remains nearly unchanged. This underlines that the latter explanatory variable indeed captures a normative concern, and is not just a proxy for the pro-sociality of the dictator. All reported effects are robust to controlling for dictator's own risk preference (model 5$)^{15}$ as well as the amount the dictator requires for selling a lottery with the same distribution of gains as the lottery to which the recipient is exposed in the respective treatment (model 6). Neither risk-preferences nor the price requested for selling the lottery add additional insights. We conclude:

Result 4: If the recipient's endowment is risky, dictators are concerned that the recipient might receive nothing. They give the more, the more they think dictators give in that situation..

15 We lose the data from participants who were inconsistent on this test since then their risk preference cannot be calculated. We can, however, instead use the result from the additional test proposed by Eckel and Grossman (2008), that forces consistency. If we do, results are consistent with the ones reported above.. 


\begin{tabular}{|c|c|c|c|c|c|c|}
\hline & model 1 & model2 & model 3 & model 4 & model 5 & model 6 \\
\hline \multicolumn{7}{|l|}{ if hurdle passed } \\
\hline reaction function cons & $\begin{array}{l}.843^{\star \star \star} \\
(.237)\end{array}$ & & & & & \\
\hline reaction function slope & $\begin{array}{l}.541 \\
(2.109)\end{array}$ & & & & & \\
\hline reaction function square & $\begin{array}{l}-1.777 \\
(21.242)\end{array}$ & & & & & \\
\hline $\begin{array}{l}\text { choice if recipient has no endow- } \\
\text { ment }\end{array}$ & & $\begin{array}{l}.663^{\star \star \star} \\
(.107)\end{array}$ & $\begin{array}{l}.495^{\star \star \star} \\
(.090)\end{array}$ & $\begin{array}{l}.462^{\star \star \star} \\
(.089)\end{array}$ & $\begin{array}{l}.424^{\star \star \star} \\
(.099)\end{array}$ & $\begin{array}{l}.398 * \star \star \\
(.107)\end{array}$ \\
\hline $\begin{array}{l}\text { choice if recipient has endowment } \\
\text { of } 5 €\end{array}$ & & $\begin{array}{l}.258^{+} \\
(.135)\end{array}$ & $\begin{array}{l}.058 \\
(.104)\end{array}$ & & & \\
\hline $\begin{array}{l}\text { expected mean choice of dictators } \\
\text { under risk }\end{array}$ & & & $\begin{array}{l}.791^{\star \star \star} \\
(.133)\end{array}$ & $\begin{array}{l}.734^{\star \star \star} \\
(.120)\end{array}$ & $\begin{array}{l}.609 \star \star \star \\
(.123)\end{array}$ & $\begin{array}{l}.587^{\star \star \star} \\
(.124)\end{array}$ \\
\hline $\begin{array}{l}\text { expected mean choice of dictators if } \\
\text { recipient has endowment of } 5\end{array}$ & & & $\begin{array}{l}-.042 \\
(.135)\end{array}$ & & & \\
\hline social value orientation & & & & $\begin{array}{l}.013+ \\
(.008) \\
\end{array}$ & $\begin{array}{l}.021^{\star *} \\
(.008) \\
\end{array}$ & $\begin{array}{l}.020 * * \\
(.008)\end{array}$ \\
\hline switching point in risk aversion test & & & & & $\begin{array}{l}.035 \\
(.054)\end{array}$ & $\begin{array}{l}.039 \\
(.052)\end{array}$ \\
\hline $\begin{array}{l}\text { willingness to accept for selling } \\
\text { equivalent lottery }\end{array}$ & & & & & & $\begin{array}{l}.053 \\
(.063)\end{array}$ \\
\hline cons & $\begin{array}{l}-.767^{+} \\
(.442)\end{array}$ & $\begin{array}{l}-.887^{+} \\
(.509)\end{array}$ & $\begin{array}{l}-1.497^{\star \star \star} \\
(.416)\end{array}$ & $\begin{array}{l}-1.439 * \star \star \\
(.425)\end{array}$ & $\begin{array}{l}-1.429 * * \\
(.585)\end{array}$ & $\begin{array}{l}-1.529 * \star \\
(.602)\end{array}$ \\
\hline \multicolumn{7}{|l|}{ hurdle } \\
\hline $\begin{array}{l}\text { does not always give nothing if } \\
\text { recipient endowment is certain }\end{array}$ & $\begin{array}{l}3.109 * * * \\
(.610)\end{array}$ & $\begin{array}{l}3.241^{\star \star \star} \\
(.783)\end{array}$ & $\begin{array}{l}2.893^{\star \star \star} \\
(.497)\end{array}$ & $\begin{array}{l}2.867 * \star \star \\
(.490)\end{array}$ & $\begin{array}{l}2.717^{\star \star \star} \\
(.493)\end{array}$ & $\begin{array}{l}2.683^{\star \star \star} \\
(.476)\end{array}$ \\
\hline cons & $\begin{array}{l}-1.713^{\star \star \star} \\
(.491)\end{array}$ & $\begin{array}{l}-1.682^{\star \star} \\
(.502)\end{array}$ & $\begin{array}{l}-1.799 * \star \star \\
(.466)\end{array}$ & $\begin{array}{l}-1.813^{\star \star \star} \\
(.463)\end{array}$ & $\begin{array}{l}-1.796^{* * *} \\
(.476)\end{array}$ & $\begin{array}{l}-1.859^{* \star *} \\
(.472)\end{array}$ \\
\hline \multicolumn{7}{|l|}{ model characteristics } \\
\hline $\mathrm{p}$ model & $<.0001$ & $<.0001$ & $<.0001$ & $<.0001$ & $<.0001$ & $<.0001$ \\
\hline $\mathrm{N}$ & 215 & 215 & 215 & 215 & 197 & 197 \\
\hline
\end{tabular}

Table 4

\section{Explanations for Dictator Choices}

double hurdle models

$\mathrm{dv}$ : choice when recipients' endowment is uncertain

data from all treatments (but not the baseline)

standard errors in parenthesis

${ }^{* * *} p<.001,{ }^{* *} p<.01,{ }^{*} p<.05,{ }^{+} p<.1$ 


\section{Conclusion}

Donors can often not be sure whether the recipient really deserves their help. One might have thought that such a risk deters generosity. In a lab experiment, we show that the opposite holds true. Those participants who are at all willing to donate give more if they have only imperfect information about the recipient's endowment. However, the transferred amount depends on the higher moments of the distribution from which the recipient's endowment is taken and not just on the first moment, i.e. the expected value, that we hold constant. Transfers decrease significantly in the standard deviation ( $2^{\text {nd }}$ moment) and increase significantly in the skewness ( $3^{\text {rd }}$ moment) of the distribution. However, dictators are most generous if they have no information at all about the recipient's endowment.

We use a series of within subjects tests to find the determinants of this evaluation function. The most important factor is the attitude of the individual dictator towards leaving the recipient with nothing. The more the dictator gives when the recipient is sure to have no endowment, the more she also gives when the recipient's endowment is risky. This suggests that dictators chiefly aim at addressing the possibility that, for the recipient, the worst comes to the worst. Dictators also give the more the more they think all dictators give in the same situation. This suggests that dictator choices are driven by normativity, and that dictators orient themselves towards what they believe to be the local norm.

At a first glance our result stands in thought-provoking contrast to another, well-documented effect: if dictators are given an opportunity to hide the ability to help, many participants seize the opportunity, even if this is costly. The effect has been graphically labelled as "moral wiggle room” (Dana, Cain et al. 2006, Dana, Weber et al. 2007) (but see van der Weele, Kulisa et al. 2014), and has been modeled as a concern for one's self-image (Benabou and Tirole 2006, Andreoni and Bernheim 2009). We show that being unsure about the recipient's deservingness has a diametrically opposite effect: it makes dictators more generous, the more so the more pronouncedly deservingness is uncertain. Actually both findings would be consistent with self-image as a common cause: in our setting, dictators know that recipients know that dictators face the risk of leaving a deserving recipient with nothing who is at their mercy.

In day-to-day life, individuals hardly ever benefit from the privilege of true certainty. Uncertainty is particularly likely if a call for help reaches them. Help is often given to those in distress. And distress is regularly accompanied by disorder. If socially minded individuals were to wait until those begging for their intervention have proven beyond doubt that they really need help, much distress would go unchecked. The results from our experiment suggest that those who are at all willing to listen to such calls for help are indeed sensitive to the frequently dismal procedural situation of potential recipients. The same as a criminal court, they would much rather accept that some of their generosity is diverted to unworthy causes, rather than risking that those who have asked legitimately for help because they are in serious trouble are left alone. Humans are social animals, after all. 


\section{References}

Andreoni, James And B. Douglas Bernheim (2009). "Social Image and the 50-50 Norm. A Theoretical and Experimental Analysis of Audience Effects." Econometrica 77: 16071636.

Andreoni, James And John Miller (2002). "Giving According to GARP. An Experimental Test of the Consistency of Preferences for Altruism." Econometrica 70: 737-753.

BARDSLey, Nicholas (2008). "Dictator Game Giving. Altruism or Artefact?" Experimental Economics 11: 122-133.

BArtling, BJörn, Florian Engl and Roberto A. Weber (2013), Does Willful Ignorance Deflect Punishment? - An Experimental Study, http://ideas.repec.org/p/zur/econwp/125.html.

Becker, Gordon M., Morris H. DeGroot And Jacob MarschaK (1964). "Measuring Utility by a Single-response Sequential Method." Behavioral Science 9(3): 226-232.

Benabou, Roland and Jean Tirole (2006). "Incentives and Prosocial Behavior." American Economic Review 96: 1652-1678.

Bolton, Gary E. And Elena KatoK (1998). "An Experimental Test of the Crowding Out Hypothesis. The Nature of Beneficent Behavior." Journal of Economic Behavior \& Organization 37: 315-333.

Bolton, Gary E. AND Axel OcKenfels (2000). "ERC: A Theory of Equity, Reciprocity and Competition." American Economic Review 90: 166-193.

Branas-Garza, Pablo, Miguel A. Durán and María Paz Espinosa (2009). "The Role of Personal Involvement and Responsibility in Unfair Outcomes." Rationality and Society 21: $225-248$.

Brennan, Geoffrey, Luis G GonzÁlez, Werner GÜth ANd M VitToria LeVAti (2008). "Attitudes toward Private and Collective Risk in Individual and Strategic Choice Situations." Journal of Economic Behavior \& Organization 67(1): 253-262.

Brock, J.Michelle, Andreas Lange And Erkut Y. OzBay (2013). "Dictating the Risks. Experimental Evidence on Norms of Giving in Risky Environments." American Economic Review 103: 415-4337.

Caballero, Gustavo A. (2014), Information Effect Regarding Inequality of Opportunities on Redistribution. A Lab Experiment, http://ideas.repec.org/p/clg/wpaper/2014-01.html. 
Cappelen, Alexander W., James Konow, Erik Ø. Sørensen and Bertil Tungodden (2013). "Just Luck. An Experimental Study of Risk Taking and Fairness." American Economic Review 103: 1398-1413.

CARPenter, JefFrey, Allison Liati And Brian Vickery (2010). "They Come to Play: Supply Effects in an Economic Experiment." Rationality and Society 22: 83-102.

Charness, Gary and Matthew Rabin (2002). "Understanding Social Preferences with Simple Tests." Quarterly Journal of Economics 117: 817-869.

Cox, James C. (2004). "How to Identify Trust and Reciprocity." Games and Economic Behavior 46: 260-281.

Cragg, John G. (1971). "Some Statistical Models for Limited Dependent Variables with Application to the Demand for Durable Goods." Econometrica 39: 829-844.

Dana, Jason, Daylian M. Cain and Robyn M. Dawes (2006). "What You Don't Know Won't Hurt Me. Costly (But Quiet) Exit in Dictator Games." Organizational Behavior and Human Decision Processes 100: 193-201.

Dana, Jason, Roberto A Weber and Jason Xi Kuang (2007). "Exploiting Moral Wiggle Room. Experiments Demonstrating an Illusory Preference for Fairness." Economic Theory 33(1): 67-80.

Eckel, Catherine C and Philip J Grossman (2008). "Forecasting Risk Attitudes. An Experimental Study Using Actual and Forecast Gamble Choices." Journal of Economic Behavior \& Organization 68(1): 1-17.

Eckel, Catherine C., Philip J. Grossman and Rachel M. Johnston (2005). "An Experimental Test of the Crowding Out Hypothesis." Journal of Public Economics 89: 15431560.

Engel, Christoph (2011). "Dictator Games. A Meta-Study." Experimental Economics 14: 583-610.

Engel, Christoph and Peter G. Moffatt (2014). "dhreg, xtdhreg, bootdhreg. Programs to Implement Double Hurdle Regression." Stata Journal 14: 778-797.

FeHr, ERnst And Klaus M. SchmidT (1999). "A Theory of Fairness, Competition, and Cooperation." Quarterly Journal of Economics 114: 817-868.

FISCHBACHER, URS (2007). "z-Tree. Zurich Toolbox for Ready-made Economic Experiments." Experimental Economics 10: 171-178. 
Fong, Christina M. (2007). "Evidence from an Experiment on Charity to Welfare Recipients. Reciprocity, Altruism and the Empathic Responsiveness Hypothesis." Economic Journal 117: 1008-1024.

Fong, Christina M. And Felix Oberholzer-Gee (2011). "Truth in Giving. Experimental Evidence on the Welfare Effects of Informed Giving to the Poor." Journal of Public Economics 95: 436-444.

Frignani, Nicola And Giovanni Ponti (2012). "Risk Versus Social Preferences under the Veil of Ignorance." Economics Letters 116(2): 143-146.

Fudenberg, Drew And David K Levine (2012). "Fairness, Risk Preferences and Independence. Impossibility Theorems." Journal of Economic Behavior \& Organization 81(2): 606-612.

GigerenZer, Gerd AND Ulrich Hoffrage (1995). "How to Improve Bayesian Reasoning Without Instruction. Frequency Formats." Psychological Review 102(4): 684-704.

Greiner, Ben (2004). An Online Recruiting System for Economic Experiments. Forschung und wissenschaftliches Rechnen 2003. K. Kremer and V. Macho. Göttingen: 79-93.

HAisley, Emily C. AND Roberto A. Weber (2010). "Self-serving Interpretations of Ambiguity in Other-regarding Behavior." Games and Economic Behavior 68(2): 614-625.

Heinrich, Timo and Joachim Weimann (2013). "A Note on Reciprocity and Modified Dictator Games." Economics Letters 121(2): 202-205.

Holt, Charles A. And Susan K. LAury (2002). "Risk Aversion and Incentive Effects." American Economic Review 92: 1644-1655.

Iriberri, NAgOre AND Pedro Rey-Biel (2011). "The Role of Role Uncertainty in Modified Dictator Games." Experimental Economics 14: 160-180.

Klempt, Charlotte and Kerstin Pull (2009), Generosity, Greed and Gambling. What Difference Does Asymmetric Information in Bargaining Make?, http://www.econbiz.de/archiv1/2009/94186_generosity_greed_gambling.pdf.

Koch, Alexander and Hans-Theo Normann (2008). "Giving in Dictator Games. Regard for Others or Regard by Others?" Southern Economic Journal 75: 223-231.

KorenoK, Oleg, Edward L. Millner And Laura Razzolini (2012). "Experimental Evidence on Inequality Aversion. Dictators Give to Help the Less Fortunate." Journal of Economic Behavior \& Organization 82: 543-547. 
Lazear, EdWARd P, Ulrike Malmendier and Roberto A Weber (2012). "Sorting in Experiments with Application to Social Preferences." American Economic Journal: Applied Economics 4(1): 136-163.

Liebrand, Wim B. And Charles G. McClintock (1988). "The Ring Measure of Social Values. A Computerized Procedure for Assessing Individual Differences in Information Processing and Social Value Orientation." European Journal of Personality 2: 217-230.

Norton, David A, Cait Poynor Lamberton and Rebecca Walker Naylor (2013). "The Devil you (don’t) Know. Interpersonal Ambiguity and Inference Making in Competitive Contexts." Journal of Consumer Research 40(2): 239-254.

Rammstedt, Beatrice and Oliver P. John (2007). "Measuring Personality in One Minute or Less. A 10-item Short Version of the Big Five Inventory in English and German." Journal of Research in Personality 41: 203-212.

Sandroni, Alvaro, Sandra Ludwig and Philipp Kircher (2013). "On the Difference Between Social and Private Goods." BE Journal of Theoretical Economics 13(1): 151-177.

SAVAge, LeOnard J. (1954). The Foundations of Statistics. New York,, Wiley.

SElten, Reinhard (1967). Die Strategiemethode zur Erforschung des eingeschränkt rationalen Verhaltens im Rahmen eines Oligopolexperiments. Beiträge zur experimentellen Wirtschaftsforschung. E. Sauermann. Tübingen, Mohr: 136-168.

Shupp, Robert, Roman M Sheremeta, DAVID SCHMidT AND JAMES WALKER (2013). "Resource Allocation Contests. Experimental Evidence." Journal of Economic Psychology 39: 257-267.

Trautmann, Stefan T (2009). "A Tractable Model of Process Fairness Under Risk." Journal of Economic Psychology 30(5): 803-813.

VAN Der Weele, JoËL J, Julija Kulisa, Michael Kosfeld And Guido Friebel (2014). "Resisting Moral Wiggle Room. How Robust Is Reciprocal Behavior?" American Economic Journal: Microeconomics 6(3): 256-264.

Van Koten, Silvester, Andreas Ortmann and Vitezslav Babicky (2013). "Fairness in Risky Environments. Theory and Evidence." Games 4(2): 208-242.

Winschel, EVguenia AND PhILIP ZAHN (2014), When Ignorance is Bliss Information Asymmetries Enhance Prosocial Behavior in Dicator Games, http://ideas.repec.org/p/ces/ceswps/_4750.html.

Yamagishi, Toshio And Nobuhiro Mifune (2008). "Does Shared Group Membership Promote Altruism? Fear, Greed, and Reputation." Rationality and Society 20: 5-30. 


\section{Appendix:}

\begin{tabular}{|c|c|c|}
\hline Treatment & $\begin{array}{c}\text { Necessary condition for any } \\
\text { positive transfer }\end{array}$ & $\begin{array}{c}\text { Lowest transfer if } \\
\text { condition is meet }\end{array}$ \\
\hline Fixed & $\beta \geq 0.5$ & 2.5 \\
\hline Symmetric & $\beta \geq 1+\alpha$ & 5 \\
\hline Right Asymmetry & $\beta \geq 0.56+0.11 \alpha$ & 5 \\
\hline Left Asymmetry & $\beta \geq 0.5$ & 2.25 \\
\hline Uniform & $\beta \geq 0.55+0.1 \alpha$ & 0.5 \\
\hline Right Skewed & $\beta \geq 0.59+0.18 \alpha$ & 0.5 \\
\hline Left Skewed & $\beta \geq 0.5$ & 1.25 \\
\hline State Space & $\beta \geq 0.54+0.09 \alpha$ & 0.5 \\
\hline Expected Value & - & - \\
\hline Ignorance & - & - \\
\hline
\end{tabular}

Table A1

Necessary minimal advantageous inequity aversion for positive transfers Based on a linear Fehr-Schmidt model. $\beta$ gives the parameter for advantageous inequity aversion and $\alpha$ for disadvantageous inequity aversion. Higher transfers are possible in the treatments for higher $\beta$ parameters (except in Symmetry and RightAsymmetry). 


\section{Instructions}

Welcome to this study.

Please note that you may not talk to the other participants at any time during the entire study. Should this happen, we will be forced to terminate the study.

Please read these instructions carefully. Depending on your decisions and those of the other participants, you can earn money in the course of the study. At the end, the total sum you have earned will be paid to you in cash. Please wait in your booth until you are called to pick up your payment. Please bring all material you have received from us in order to pick up your earnings.

In this study, you will interact anonymously with other participants. At no time will you find out the name of the other participant with whom you are interacting or have interacted. We will not publish any information on the decisions and payments of individual participants.

This study is made up of ten different parts, each of which is separate from the other parts. This means that your payments and decisions in one part of the study do not influence payments in later parts. On the next page, you will find the instructions to the first part of today's study.

Following these instructions, we will ask you some control questions. The study will begin once you have correctly answered these questions. The control questions are there to help you understand the instructions; they do not have any influence on your payments. 


\section{Instructions for the first part of the study}

There are two roles in the first part of the study: the role of donor and the role of receiver. At the beginning, the computer determines your role at random. In a further draw, the computer matches one donor and one receiver. Participants in the donor role receive an endowment of

\section{Euro.}

Participants in the receiver role receive an endowment that is either

$$
0,1,2,3,4,5,6,7,8,9 \text {, or } 10 \text { Euro. }
$$

The following graph shows the endowments that are possible for the receiver and how they relate to the donor's endowment.

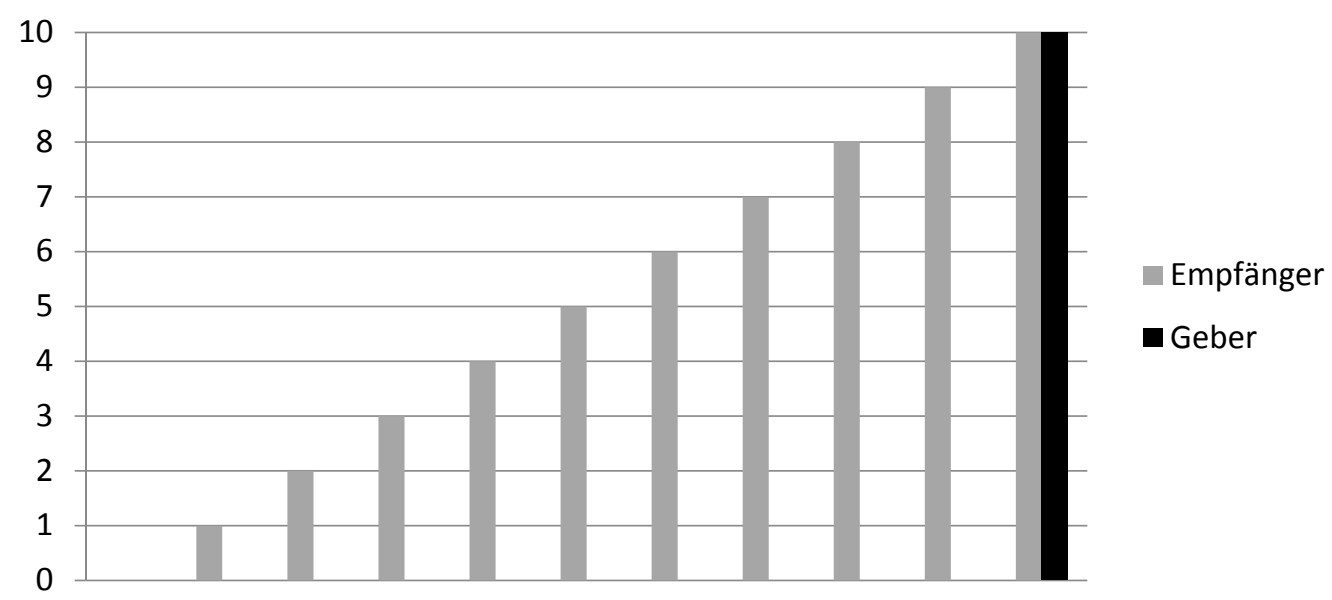

The donor now makes a decision as to how much of his or her endowment to give to the receiver. The donor can keep the entire endowment, donate the entire endowment to the receiver, or donate any other (whole-number) sum. In so doing, the donor has to make a decision for each of the eleven possible endowments of the receiver. At this point, the receiver's endowment has not yet been determined. In other words, the donor does not yet know the value of the receiver's endowment, but the donor can determine an amount - for every possible endowment value - that he or she wishes to give to the receiver.

After the donor has made decisions for all cases, the computer will determine the receiver's endowment in another draw. Please note that the computer only chooses one of the eleven possible cases and only one of these cases is paid out to the donor and the receiver in the end. We will only inform you at the end of the study, i.e., after all payoffs have been determined, which endowment the receiver actually had.

If you have any questions, please raise your hand, and we will come to you. 


\section{Instructions for the second part of the study (Treatment Symmetry)}

In the second part of the study, we have the same two roles, donor and receiver. In this second part, you keep the same role you already had in the first part of the study. However, the computer determines in a new draw which donors and receivers are matched. This draw is conducted independently of the first part of the experiment.

The donor receives an endowment of

\section{Euro.}

The receiver's endowment is determined at random by the computer:

\section{With a probability of $50 \%$, the receiver will get an endowment of 0 Euro.}

\section{With a probability of $50 \%$, the receiver will get an endowment of 10 Euro.}

For better comprehension, a graph will illustrate the type of insecurity, and its extent, on the following page. The possible receiver endowments can be seen on the vertical axis. The probability with which these endowments are realized can be seen on the horizontal axis. The computer will draw a random number between 1 and 10,000, which we shall call a lottery number. Each lottery number is allocated to an endowment, and the more lottery numbers are allocated to an endowment, the likelier it is for this endowment to be drawn. The graph shows how many lottery numbers are allocated to a payment. The above probabilities arise from the drawn lottery numbers and the total number of tickets.

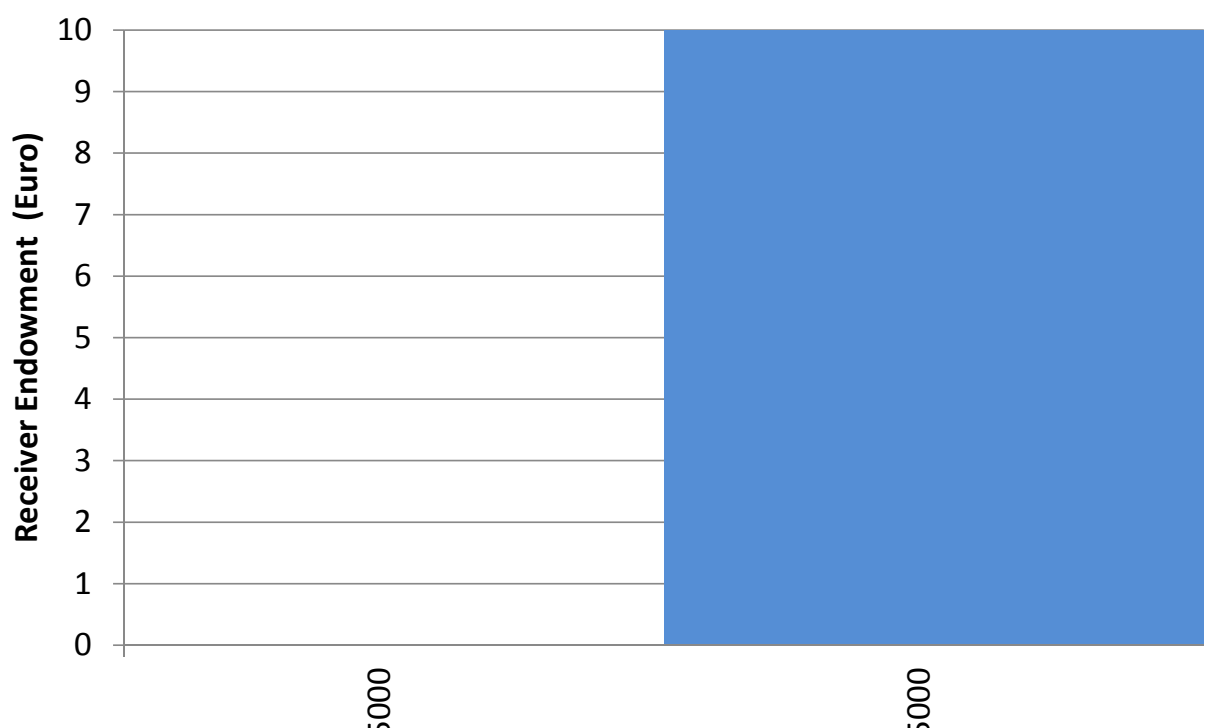

Number of lottery tickets (from an urn with 10,000 tickets) that lead to the corresponding endowment

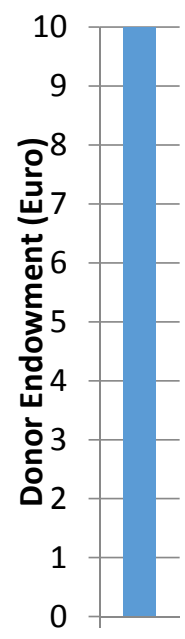

For comparison, a further graph shows the donor's secure endowment. 
The donor now makes a decision as to how much of his or her endowment to give to the receiver. The donor can keep the entire endowment, donate the entire endowment to the receiver, or donate any other (whole-number) sum.

Please note that this time the donor may not determine the amounts given to the receiver for the possible receiver endowments. The donor only knows

1. which receiver endowments are possible

$$
\text { (0 or } 10 \text { Euro); }
$$

2. how likely it is that the passive participant will receive all of these endowments

$$
\text { (a likelihood of 50\%). }
$$

Only at the end of this study, once the donor's decision has come into effect, will we inform you of the endowment the receiver actually had.

Before you make your decision in a few moments, we will ask you to answer two control questions that check your understanding of the material so far. Once you have answered all questions correctly, the payoff-relevant part will begin.

If you have any questions, please raise your hand, and we will come to you.

Depending on treatment, the graph was replaced by one of the following graphs: 


\section{Lottery}

With a probability of $50 \%$, you will receive 10 Taler. With a probability of $50 \%$, you will receive 0 Taler. There may be two possibilities, but only one of these cases appears in the graph.

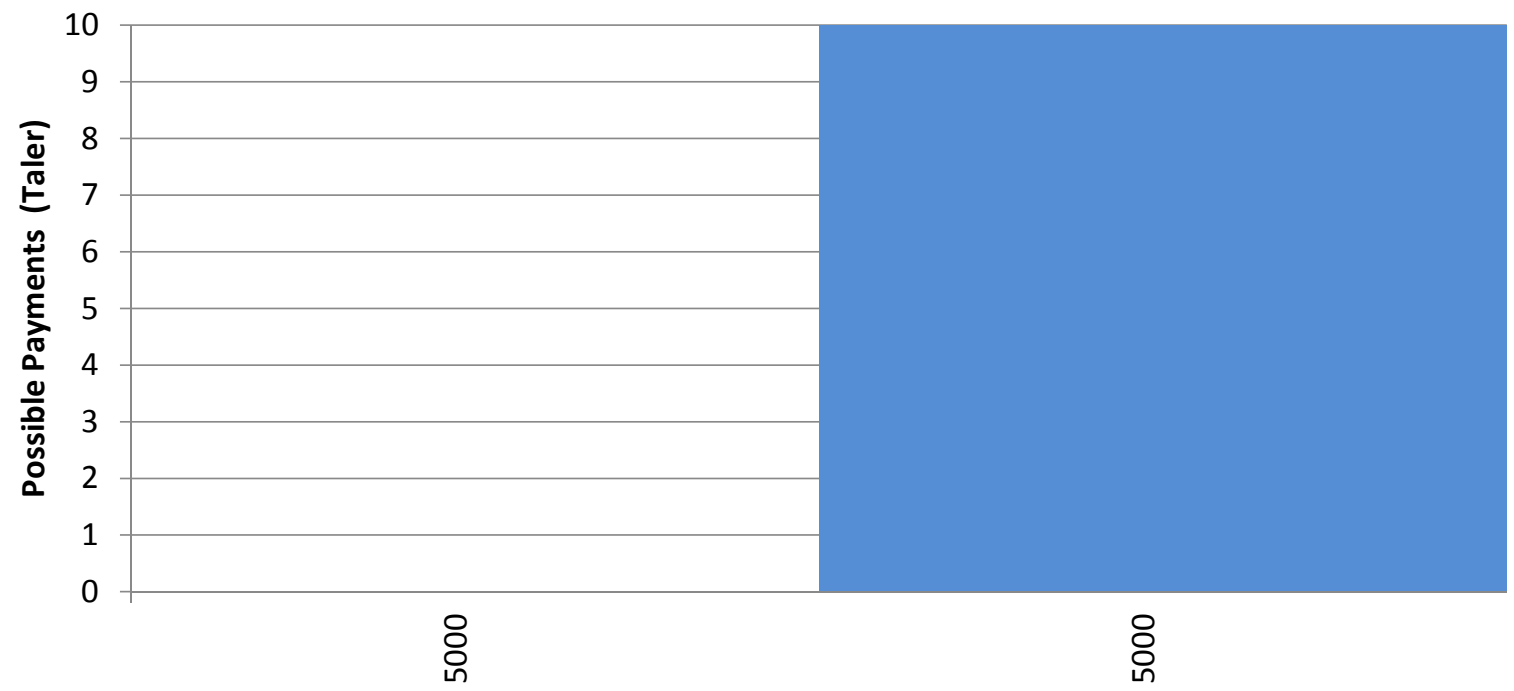

Number of lottery tickets (from an urn with 10,000 tickets) that lead to the corresponding endowment 


\section{Lottery}

In this lottery, there are two possible payments. The first payment (of 0 Taler) will occur with a probability of $90 \%$ ein, while the other payment (of 50 Taler) will occur with a probability of $10 \%$. Please be aware that in this lottery, too, one of the two payments is 0 Taler and therefore not visible in the graph.

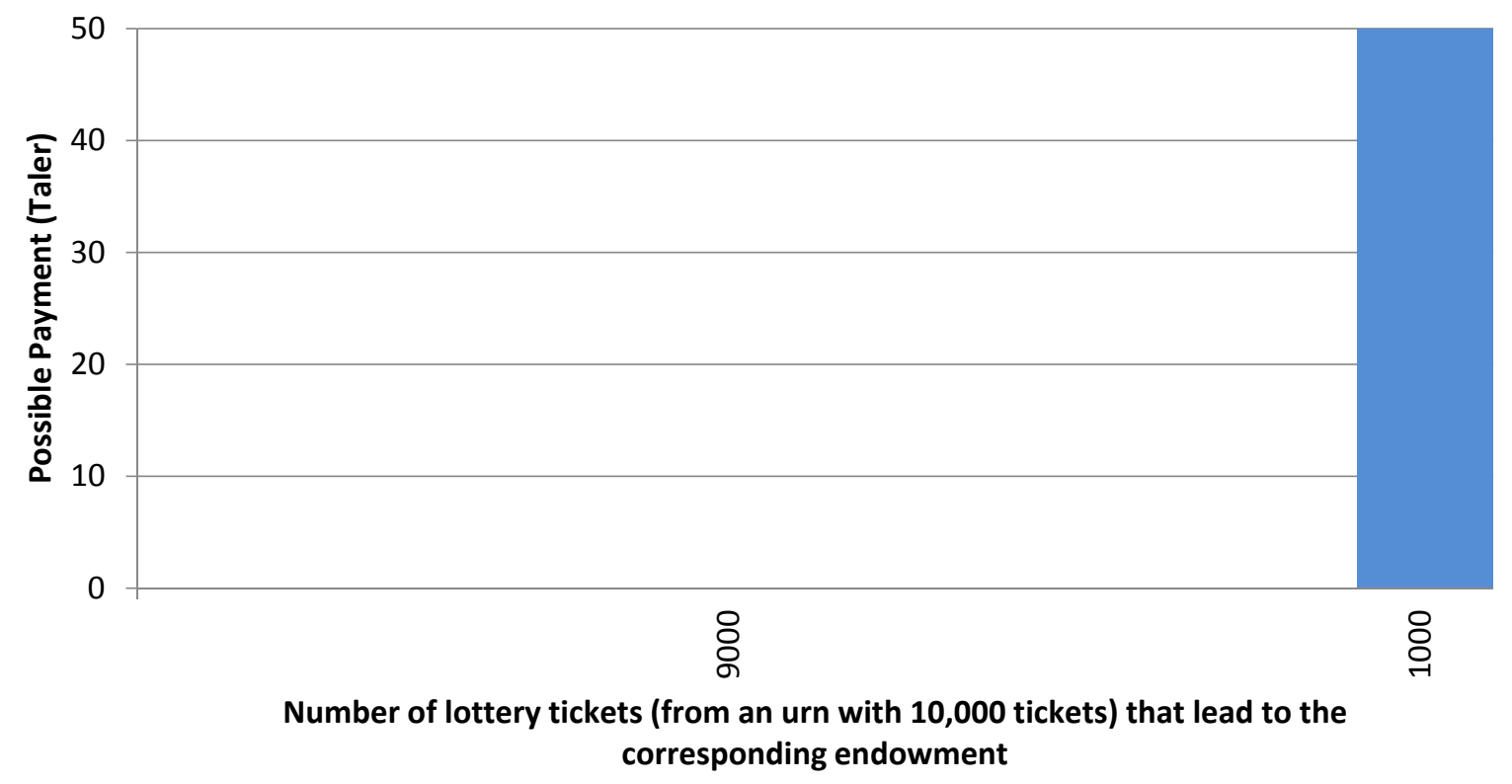




\section{3. Lottery}

In this lottery, there are two possible payments. The first payment (of 0 Taler) will occur with a probability of $10 \%$, while the other payment (of 5.5 Taler) will occur with a probability of 90 $\%$. Please be aware that in this lottery, too, one of the two payments is 0 Taler and therefore not visible in the graph.

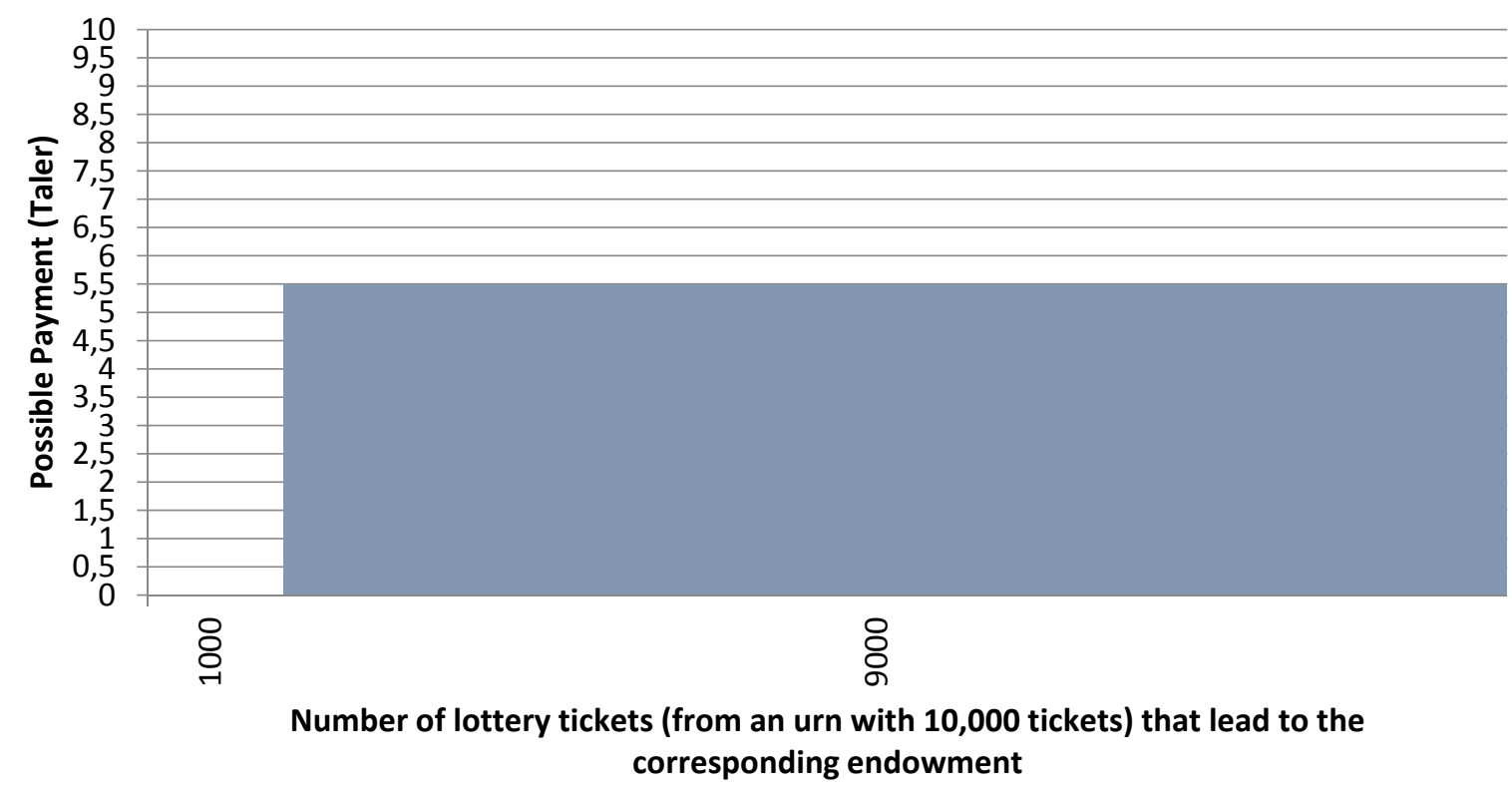




\section{4. Lottery}

In this lottery, there are 11 possibilities. Your earnings can be any whole number between 0 and 10 Taler, with an equal probability of $9 \%$.

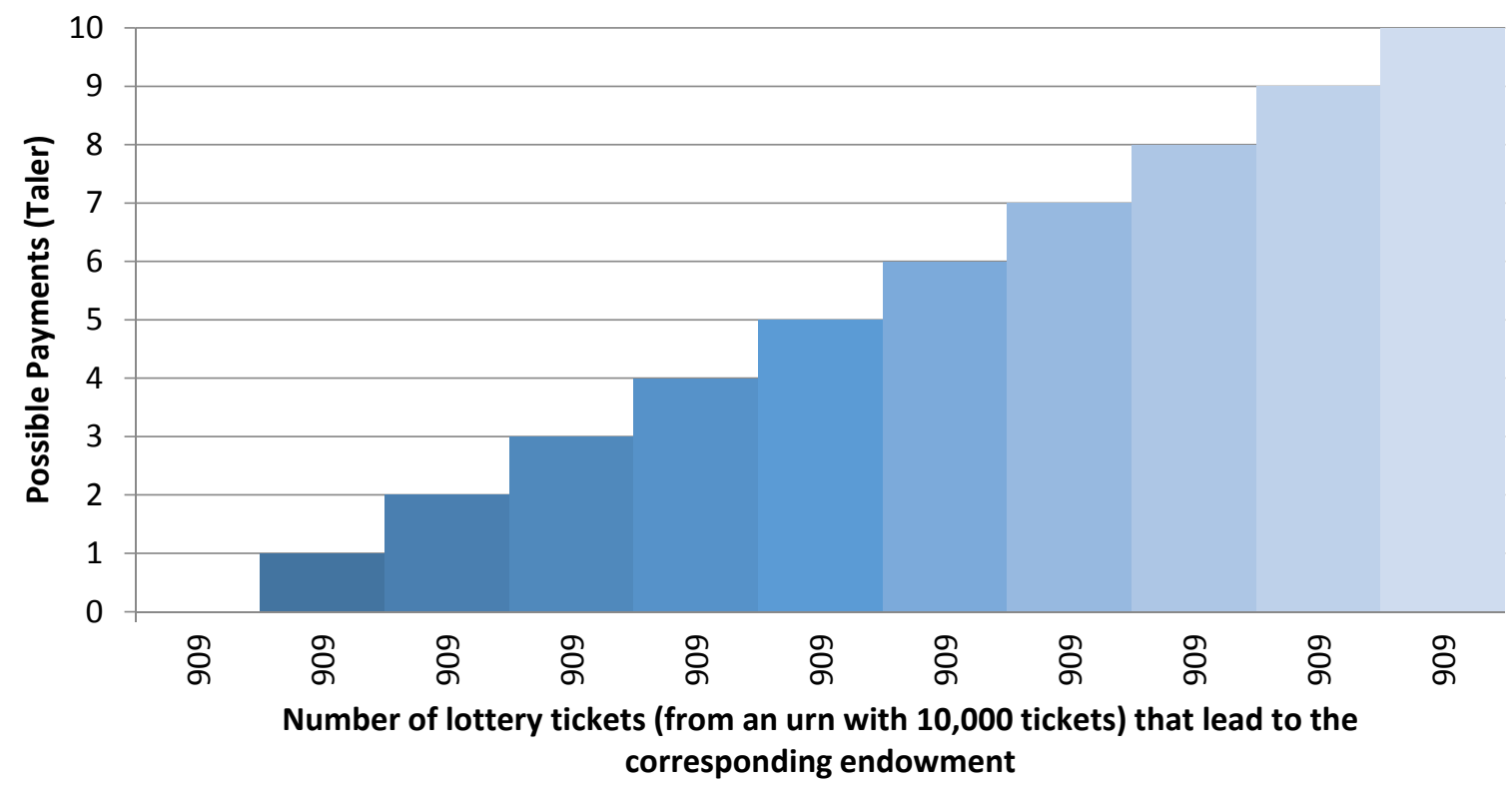




\section{Lottery}

In this lottery, there are 11 possibilities. The winnings can be anything between 0 and $15 \mathrm{Ta}$ ler, in equal steps of 1.5 Taler. However, the different realizations of the winnings have different (rather than equal) probabilities.

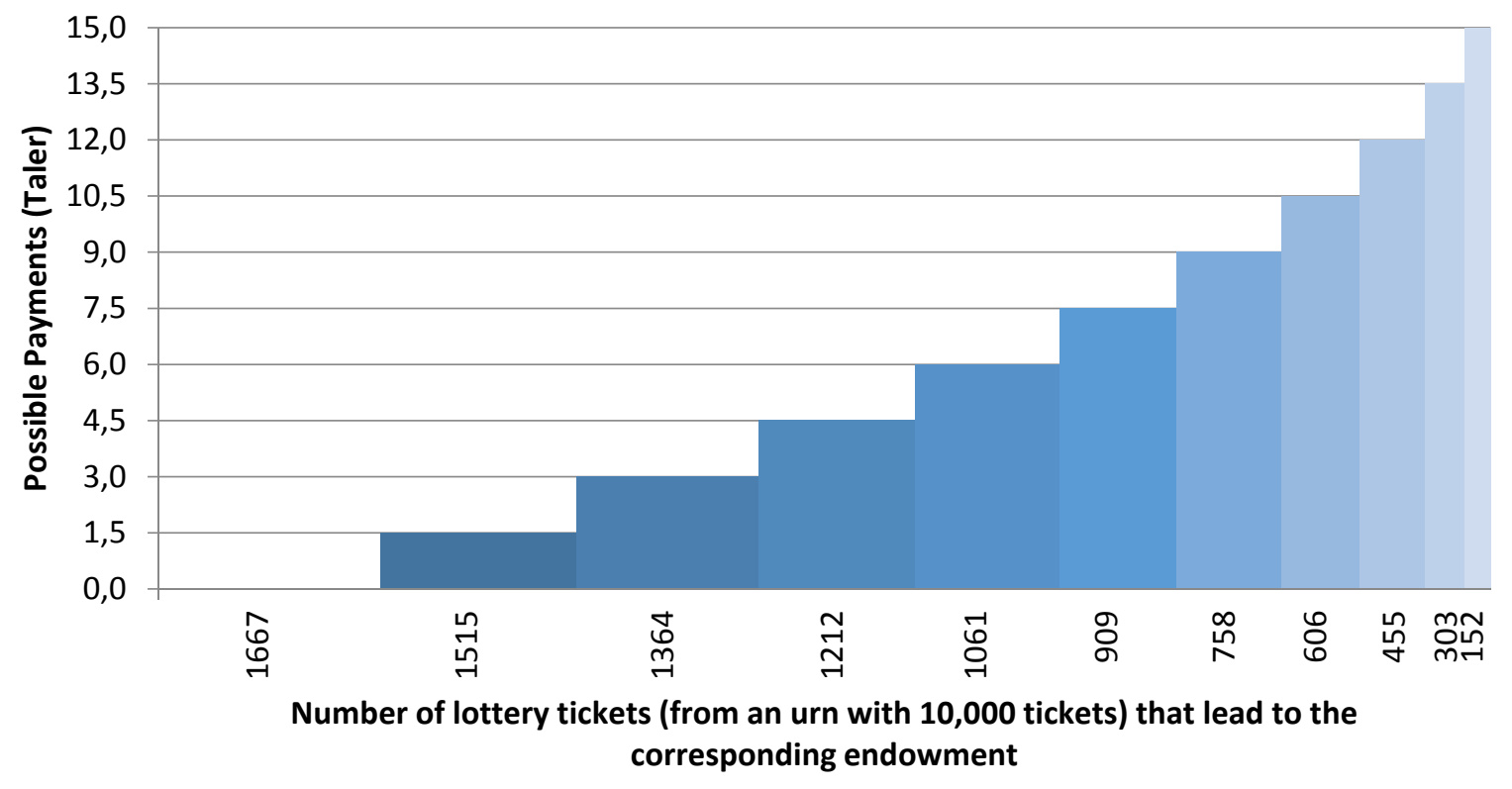




\section{Lottery}

In this lottery, there are 11 possibilities. The winnings can be anything between 0 and 6.66 Taler, in equal steps of .66 Taler. However, the different realizations of the winnings have different (rather than equal) probabilities.

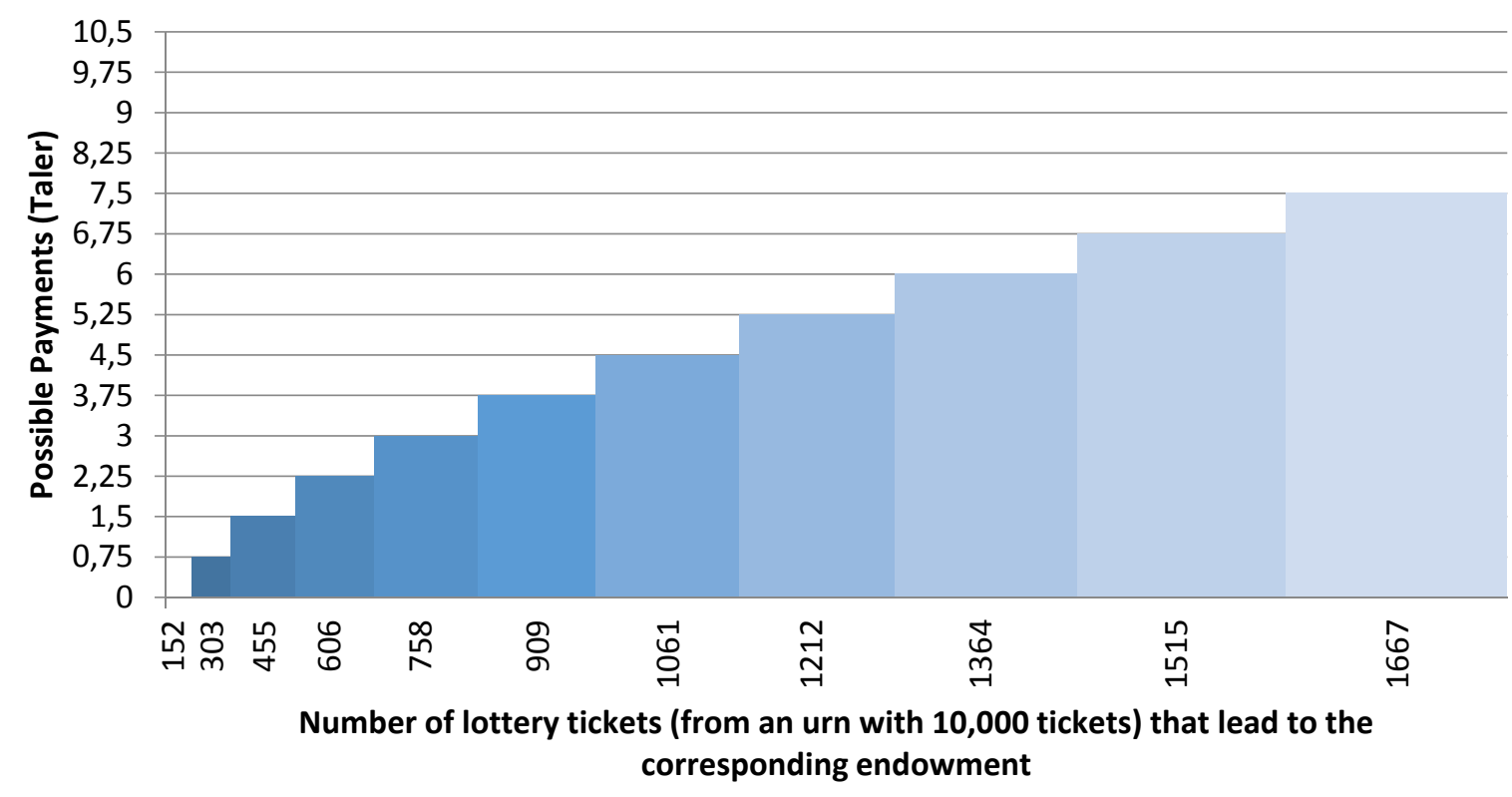




\section{Lottery}

This lottery consists of one of the three lotteries 5,6 , and 7 , all of which can occur with the same probability, i.e., a probability of $33.3 \%$.

\section{Lottery}

In this lottery, we know that, after 1,000 repetitions, 5 Taler occur on average.

\section{Lottery}

In this lottery, we do not know the winnings that can occur, nor how many possibilities there are, nor which probabilities are assigned to these possibilities. Only losses are excluded. 


\section{Instructions for the third part of the study}

In this part of the experiment, you are matched with no other participant. You therefore decide alone. We ask you for your estimate.

1. In your opinion, how many Euro, on average, did the donors decide to give the receiver in the first part of the study, if the receiver had an endowment of 5 Euro?

2. In your opinion, how many Euro, on average, did the donors give the receiver in the second part of the study?

For each of your estimates that are no more that $\mathbf{+ 1}$ or $\mathbf{- 1}$ away from the actual number, you will be given an additional payoff of 1 Euro.

If necessary, you may re-read the instructions to the first and second part of this study.

If you have any questions, please raise your hand, and we will come to you. 


\section{Instructions for the fourth part of the study}

In this part of the experiment, your decisions are relevant only to you and influence only your own payment. Similarly, the other participants' decisions only influence their own respective payments. In this and the following parts, we will give the payment sums in the fictitious Taler currency. 1 Taler corresponds to 0.1 Euro.

In a few moments, we will show you a lottery on your screen and ask you what the minimum price would be for which you would be willing to sell this lottery. The price can be anything between 0 and 10 Taler. Once you have determined a price, the computer will draw a whole number between $\mathbf{0}$ and $\mathbf{1 0}$ Taler. All numbers are equally likely. Should this number be higher than your price, the computer will buy the lottery from you at the chosen price. Should the number be lower than your price, the computer will not buy the lottery from you.

If you keep the lottery, the computer will play this lottery in the next step and credit the profit to you. If the price you named is lower than the number determined by the computer, the lottery is sold to the computer at the price determined by you.

The lottery is described on your screen by way of a table containing probabilities. Apart from the possible profit, the table contains the probabilities with which this profit occurs. For better comprehension, we shall also illustrate the type and extent of the insecurity by way of a graph. The possible profit can be seen on the vertical axis. The probability with which this profit occurs can be seen on the horizontal axis. The computer will randomly draw a number between 1 and 10,000, which we shall call lottery number. Each lottery number is assigned to one profit, and the more lottery numbers are allocated to a profit, the likelier it is for this profit to be drawn. The graph shows how many lottery numbers are allocated to a payment. The probabilities in the table arise from the drawn lottery numbers and the total number of tickets.

If you have any questions, please raise your hand, and we will come to you. 


\section{Lottery (Treatment Symmetry)}

With a probability of $50 \%$, you will receive 10 Taler. With a probability of $50 \%$, you will receive 0 Taler. There may be two possibilities, but only one of these cases appears in the graph.

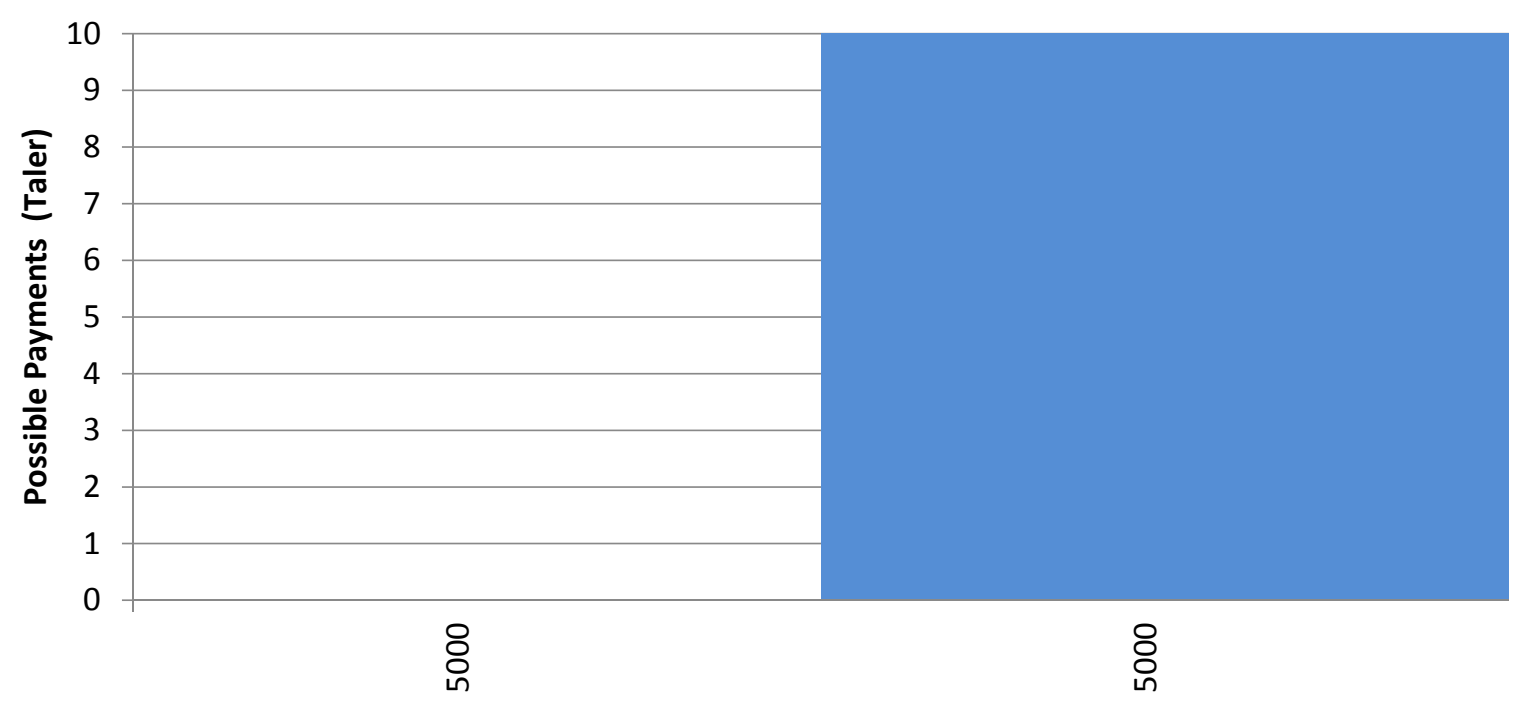

Number of lottery tickets (from an urn with 10,000 tickets) that lead to the corresponding endowment 


\section{Instructions for the fifth part of the study}

In this part of the experiment, too, your decisions are only relevant for you and influence only your own payment. Similarly, the other participants' decisions only influence their own respective payments.

In this part, you are asked to opt for one of five lotteries. Each of the lotteries has two possible payoffs, both of which are equally probable (in other words, they can occur with a probability of 50\%). The lottery chosen by you will be played out at the end of this study, and the resulting payment will be added to your total earnings.

\begin{tabular}{|c|c|c|c|c|}
\hline Lotterie: & Los: & Auszahlung (Taler): & Wahrscheinlichkeit: & Ihre Auswahl: \\
\hline \multirow{2}{*}{1} & A & 10.0 & $50 \%$ & Lotterie 1 \\
\hline \multirow{2}{*}{2} & B & 10.0 & $50 \%$ & \\
\hline \multirow{2}{*}{3} & A & 18.0 & $50 \%$ & \\
& B & 6.0 & $50 \%$ & Lotterie 2 \\
\hline 4 & A & 26.0 & $50 \%$ & Lotterie 3 \\
\hline & B & 2.0 & $50 \%$ & \\
\hline & A & 34.0 & $50 \%$ & Lotterie 4 \\
\hline & B & -2.0 & $50 \%$ & Lotterie 5 \\
\hline
\end{tabular}

Bitte entscheiden Sie sich fur eine Lotterie, durch bestătigen einer der fünf Buttons.

If you have any questions, please raise your hand, and we will come to you. 


\section{Instructions for the sixth part of the study}

In this part, we ask you to make a series of decisions once again. In this part of the experiment, too, your decisions are only relevant for you and influence only your own payment. Similarly, the other participants' decisions only influence their own respective payments. How much you ultimately receive depends on your decisions and on chance.

For each of the 10 lines in the table you have to decide between option A and option $\mathrm{B}$. At the end of the experiment, a line is randomly drawn and thus becomes relevant for your payoff. Each line can be chosen with the same probability. You should therefore consider your choice carefully for each line.

\begin{tabular}{|c|c|c|c|}
\hline Lotterie & Option A & Option B & Ihre Entscheidung \\
\hline 1 & $\begin{array}{l}20 \text { Taler mit Wahrscheinlctket } 10 \% \text { oder } \\
16 \text { Taler mit Wahrscheinlchkeit } 90 \%\end{array}$ & $\begin{array}{l}\text { 38.5 Taler mit Wahrscheinlichkeit } 10 \% \text { oder } \\
\text { 1 Taler mit Wahrscheinilchkett } 90 \%\end{array}$ & $\begin{array}{l}\text { Coston A } \\
r \text { Oston B }\end{array}$ \\
\hline
\end{tabular}

You will find these ten cases in a list on your screen. Both options consist of two possible payments (one high and one low), which are paid out with varying probabilities. 


\section{Instructions for the seventh part of the study}

In this part, we ask you to make a series of decisions once again. In this part of the experiment, too, your decisions are only relevant for you and influence only your own payment. Similarly, the other participants' decisions only influence their own respective payments. How much you ultimately receive depends on your decisions and on chance.

For each of the 20 lines in the table you have to decide between option A and option B. At the end of the experiment, a line is randomly drawn and thus becomes rellevant for your payoff. Each line can be chosen with the same probability. You should therefore consider your choice carefully for each line.

You will be shown 20 different lotteries. If, for instance, you have chosen option B in one line, you will be certain to receive the sum from option $B$ in case the computer chooses this line at the end of the experiment. In the case of option $A$, the computer will determine the result of the lottery by way of another draw.

\begin{tabular}{c|c|c|c} 
Lotterie & \multicolumn{1}{|c|}{ Option A } & Option B & Ihre Entscheidung \\
\hline 1 & $\begin{array}{l}5.00 \text { Taler mit unbekannter Wahrscheinlichkeit oder } \\
0.00 \text { Taler mit unbekannter Wahrscheinlichkeit }\end{array}$ & 0.25 Taler garantiert & Option A $r r$ Opton B
\end{tabular}




\section{Instructions for the eighth part of the study}

In this part of the study, your payment once again depends on the other participants' decisions, just as your decisions influence the other participants' payments.

Each participant is asked to choose a number between 1 and 100 . Whoever lies closest to two-thirds of the average of all chosen numbers wins this eighth part of the study. In other words, the computer first calculates the average of all numbers and multiplies this number by .67. Then the computer determines the participant whose number was closest to this number. The winner receives 50 Taler. Should several participants be equally close to two-thirds of the average, the 50 Taler shall be equally distributed.

If you have any questions, please raise your hand, and we will come to you. 


\section{Instructions for the ninth part of the study}

For this ninth part, you must once again make decisions that have an influence on a partner with whom you have been randomly matched. Each time, you decide between two distributions that allocate Taler to you and your partner. At the same time, you are also randomly assigned to another partner who also allocates Taler to you by choosing distributions. This participant is not the same person as the one to whom you can allocate Taler.

You are now asked to choose 32 times between two distributions, $X$ and $Y$. The distributions can also contain negative payments for the other participant or for you. The Taler that you allocate to yourself are paid to you at the end of the study. Here, too, negative payments are possible. The Taler that the other participant allocates to you are also noted on your account and paid to you at the end of the study.

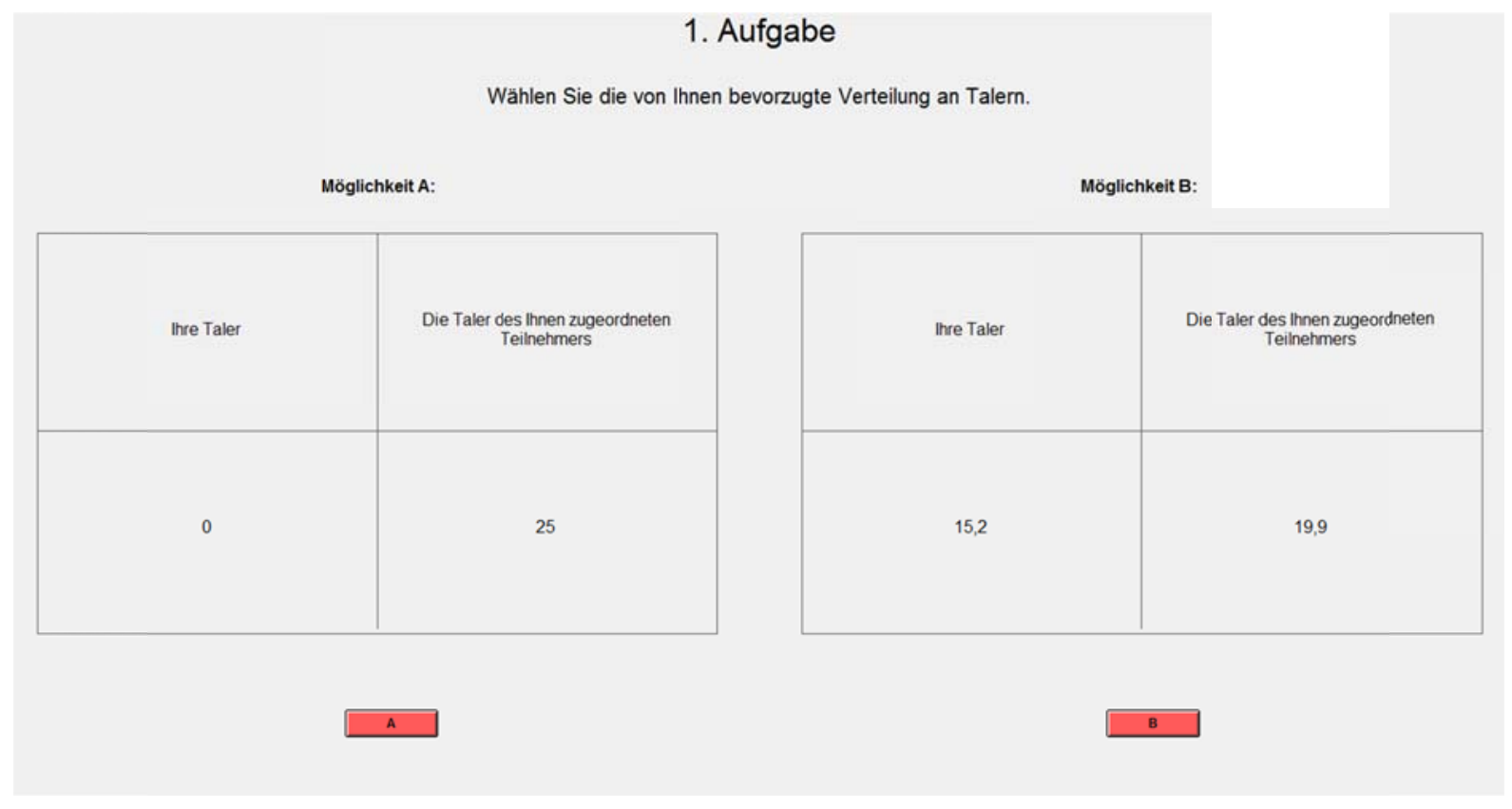

The ninth part of the study is the last payoff-relevant part. After this part, we only have a few questions that are intended to help our analysis of the experiment and that are obviously also anonymous. In the meantime, we will calculate your total earnings and call you individually, in the sequence of the booth numbers, to pick up your payment. Please bring all material of this experiment with you. Please leave your booth clean and empty. 